MIGRATION AND THE WELFARE STATE: A DYNAMIC POLITICAL-ECONOMY THEORY

\author{
Assaf Razin \\ Efraim Sadka \\ Benjarong Suwankiri \\ Working Paper 15597 \\ http://www.nber.org/papers/w15597 \\ NATIONAL BUREAU OF ECONOMIC RESEARCH \\ 1050 Massachusetts Avenue \\ Cambridge, MA 02138 \\ December 2009
}

This paper was previously circulated as "The Welfare State and the Skill Mix of Migration: Dynamic Policy Formation." The views expressed herein are those of the author(s) and do not necessarily reflect the views of the National Bureau of Economic Research, TMB Bank Plc. Ltd. or its executives.

NBER working papers are circulated for discussion and comment purposes. They have not been peerreviewed or been subject to the review by the NBER Board of Directors that accompanies official NBER publications.

(C) 2009 by Assaf Razin, Efraim Sadka, and Benjarong Suwankiri. All rights reserved. Short sections of text, not to exceed two paragraphs, may be quoted without explicit permission provided that full credit, including $\odot$ notice, is given to the source. 
Migration and the Welfare State: A Dynamic Political-Economy Theory

Assaf Razin, Efraim Sadka, and Benjarong Suwankiri

NBER Working Paper No. 15597

December 2009, Revised February 2012

JEL No. F0,H0

\begin{abstract}
We develop a dynamic politico-economic theory of welfare state and immigration policies, featuring three groups of voters: skilled workers, unskilled workers, and old retirees. The welfare-state is modeled by a proportional tax on labor income to finance a demogrant in a balanced-budget manner to capture the essence of inter- and intra- generational redistribution of a typical welfare system. Migrants arrive when young and their birth rate exceeds the native-born birth rate. We characterize political-economic equilibrium policy rules consisting of the tax rate, the skill composition of migrants, and the total number of migrants, in terms of demographic and labor productivity characteristics. We find that political coalitions will form among skilled and unskilled voters or among unskilled and old voters in order to block the other group from coming into power. As a consequence, the ideal policies of the unskilled voters are featured more often in the political economy equilibria than any other groups regardless of the size of unskilled voters.
\end{abstract}

Assaf Razin

Department of Economics

Cornell University

Uris 422

Ithaca, NY 14853

and Cornell University

and also NBER

ar256@cornell.edu

Efraim Sadka

Tel Aviv University

Eitan Berglas School of Economics

P.O.B. 39040

Ramat Aviv, Tel Aviv, 69978, ISRAEL

sadka@post.tau.ac.il
Benjarong Suwankiri

Department of Economics

Cornell University

Ithaca, NY

14853

bs246@cornell.edu 


\title{
Migration and the Welfare State: A Dynamic Political-Economy Theory
}

\author{
Assaf Razin* Efraim Sadka ${ }^{\dagger}$ Benjarong Suwankiri ${ }^{\ddagger}$ \\ January 152012
}

\begin{abstract}
We develop a dynamic politico-economic theory of welfare state and immigration policies, featuring three groups of voters: skilled workers, unskilled workers, and old retirees. The welfare-state is modeled by a proportional tax on labor income to finance a demogrant in a balanced-budget manner to capture the essence of inter- and intragenerational redistribution of a typical welfare system. Migrants arrive when young and their birth rate exceeds the native-born birth rate. We characterize political-economic equilibrium policy rules consisting of the tax rate, the skill composition of migrants, and the total number of migrants, in terms of demographic and labor productivity characteristics. We find that political coalitions will form among skilled and
\end{abstract}

*Department of Economics, Cornell University, Ithaca, NY 14850 USA and The Eitan Berglas School of Economics, Tel-Aviv University, Tel Aviv 69978, ISRAEL. E-mail: razin@post.tau.ac.il

†The Eitan Berglas School of Economics, Tel-Aviv University, Tel Aviv, 69978 ISRAEL. E-mail: sadka@post.tau.ac.il

†The views expressed in this paper are those of the author(s) and do not necessarily represent those of TMB Bank Plc. Ltd. or its executives. Corresponding Author: Benjarong Suwankiri, TMB Bank Public Co. Ltd., TMB Analytics, 3000 Pahonyothin Rd., Chomphon, Chatuchak, Bangkok, 10900 THAILAND. E-mail: benjarong.suw@tmbbank.com, Phone: (66)2-299-2645, Fax: (66)2-242-3506. 
unskilled voters or among unskilled and old voters in order to block the other group from coming into power. As a consequence, the ideal policies of the unskilled voters are featured more often in the political economy equilibria than any other groups regardless of the size of unskilled voters.

JEL Classification: D7, F2 and H5

Keywords: Generosity of Welfare State, Pay As You Go, Markovperfect Political Equilibrium, Strategic Voting, and Skill Composition of Migration

\section{Introduction}

Milton Friedman reminded us that, obviously, one cannot have free immigration and a generous welfare state, at the same time. Indeed, public opinion in the developed economies, with a fairly generous welfare system, favors putting in some way or another restrictions on migration (see, for example, Hanson, Scheve, and Slaughter (2007, 2009)). A skilled and young migrant may help the finances of the welfare state; whereas an unskilled and old migrant may inflict a burden on the welfare state. A welfare state with a heterogeneous (by age, skill, etc.) population does not evidently have a commonly accepted attitude towards migration. This paper develops a framework to study how these inter- and intra-generational conflicts, among different age and income groups, is resolved in a politico-economic setup. Of a particular interest is how an economy with more than just two groups of voters resolve the conflicts between more demand for welfare state redistribution and and the skill composition of immigration policy.

A typical welfare state is characterized by both inter-generational redistribution (such as old-age social security) and intra-generational redistribution (such as income maintenance programs). ${ }^{1}$ Accordingly, our overlapping gen-

\footnotetext{
${ }^{1}$ Some features of the welfare state, such as national health insurance, involve both inter- and intra-generational redistribution.
} 
erations model is based on key demographic characteristics: that migrants are younger and have higher birth rates than the native born population. The model also features two income levels, skilled labor and unskilled labor. People live for two periods and votings about the current migration and the generosity of the welfare state are jointly conducted in each period. We employ the Markov-perfect equilibrium concept, as in Krusell and Rios-Rull (1996), and Hassler et al. (2003). The forward-looking equilibrium concept means that each young voter takes into account the effect of her vote on the evolution of the economy into the next period; which, in turn, affects the voting outcome in the next period, particularly with respect to the social security benefit that she receives in the next period, when she grows old and retires Next period voting, in turn, is influenced by the outcome of the voting outcome in the following period, and so on. Since a welfare state will necessarily affect more than two groups of voters, of particular interest is the characterization of possible coalitions which emerge as decisive in the political-economic equilibria, for different demographic and skill-distribution parameters. In this regard, we depart from the typcial literature markedly whose focus was mainly on the conflict between only two groups: either young versus old voters (for example, Boldrin and Rustichini (2000), Sand and Razin (2007)), or skilled versus unskilled voters (see for example Hassler et al. (2003), Dolmas and Huffman (2004), and Armenter and Ortega (2011)). Our paper took a novel step in trying to resolve political conflcts between three groups of voters, which amounts to strategic voting thus forming coalition to defeat the most undesirable policy outcome. Not only that this is an amalgamate of the two lines of literature, it also provides an alternative mechanism for future research.

The paper is organized as follows. Section 2 discusses earlier literature and some evidence for the existence of the fiscal burden of migration. Section 3 presents the analytical framework. Section 4 characterizes the equilibrium policy rules under sincere voting. Section 5 extends the analysis of policy rules under sincere voting to the case of endogenous wages. Section 6 char- 
acterizes the political-economy equilibrium under strategic voting. Section 7 concludes.

\section{Background Literature and Fiscal Burden}

Our paper is directly related to two fields of the existing political economy literature: the political economy of the PAYG social security systems (Cooley and Soares (1999), Bohn (2005), Boldrin and Rustichini (2000), Galasso (1999)) and the political economy of migration (such as Benhabib (1996) and Ortega (2005)). The view that increased migration may come to the rescue of PAYG social security systems reflects the fact that the flow of migrants can alleviate the current demographic imbalance as well, by influencing the age structure of the host economy. A few empirical studies address this point by calibrating the equilibrium impact of a less restrictive policy towards migration according to U.S. data. Storesletten (2000) found in a general equilibrium model that selective migration policies, involving increased inflow of working-age high and medium-skilled migrants, can remove the need for a future fiscal reform. Auerbach and Oreopoulos (1999) performed the like exercise using partial equilibrium generational accounting and arrived at similar conclusion. By emphasizing the demographic side and abstracting from the migrants' factor prices effects, Lee and Miller (2000) concluded in a similar analysis that a higher number of migrants admitted into the economy can ease temporarily the projected fiscal burden of retiring babyboomers. There are also a few studies which deal with the effect of migrants on the PAYG social security system (Razin and Sadka (1999) and Scholten and Thum (1996)). This paper addresses the joint political economy decisions regarding both migration policy and social security policy, and hence, the welfare state, in a dynamic setup.

There have been previous works on the political economy of immigration and redistribution policies, albeit focussed solely on either inter-generational or intra-generational alone. Razin, Sadka, and Swagel (2002b), and Casarico 
and Devillanova (2003) focussed on the impact of immigration the political economy of inter-generational redistribution. Sand and Razin (2007) took an additional step to provide a synthesis on the political economy model jointly determining the inter-generational redistribution and immigration. Dolmas and Huffman (2004) analyzed similarly the joint determination of intra-generational redistribution and immigration policy in a dynamic political economy model. This paper amalgamates these two lines of research, as noted, allowing for a redistribution across both inter- and intra-generations. Armenter and Ortega (2011), while also studied redistribution and skilled migration, focussed more on explaining the geographical concentration of skilled labor as triggered by credible redistribution policy. Our focusse are more on the interaction of policies, between welfare state and immigration policy, and on political resolution via strategic voting and fprmation of political bloc.

The European Union, both "old" (EU-15) and "new" (after the enlargement to EU-27), faces a severe aging problem. For instance the ratio of the elderly population (aged 60 years and over) to the working age population (aged 15-59 years) in the EU-15 is projected to at least double from about $20 \%$ in the year 2000 to over $40 \%$, in the year 2050. Official retirement ages have failed to keep up with life expectancy, making pensions and health care provisions increasingly unaffordable. "Many people in the rich-world OECD countries retire relatively early, which let them enjoy, on average, some 19 years in retirement before death." (The Economist, February 2nd, 2010). Years in retirement in Italy, Austria and France are 23, 24 and 25, respectively. The aging process shakes the financial soundness of the welfare state, especially its old-age security and medical health components, because there are fewer workers asked to support increasing numbers of retirees. As put metaphorically by the Economist (March 15th, 2003, 80):..." the fiscal burden on the diminishing number of worker-bees will rise as more people turn into pensioner drones." The Economist (24th August, 2002) also looks at some of the dimensions of the financial burden: "On some estimates, by 2050, government debt could be equivalent to almost 100 percent of national 
income in America, 150 percent in the EU as a whole [EU-15] and over 250 percent in Germany and France." Nevertheless, note that migration of young workers (as distinct from retirees), even when driven by the generosity of the welfare state, slows down the trend of increasing the dependency ratio. However, economic intuition suggests that even though unskilled migration improves the dependency ratio, it nevertheless burdens the welfare state. This is because low-skill migrants are typically net beneficiaries of the generosity of the welfare state. Indeed, in 1997 the U.S. National Research Council sponsored a study on the overall fiscal impact of immigration into the U.S.; see Edmonston and Smith (1997). The study looks comprehensibly at all layers of government (federal, state, and local), all programs (benefits), and all types of taxes. For each cohort, defined by age of arrival to the U.S., the benefits (cash or in kind) received by migrants over their own lifetimes and the lifetimes of their first-generation descendants were projected. These benefits include Medicare, Medicaid, Supplementary Security Income (SSI), Aid for Families with Dependent Children (AFDC), food stamps, Old Age, Survivors, and Disability Insurance (OASDI), etc. Similarly, taxes paid directly by migrants and the incidence on migrants of other taxes (such as corporate taxes) were also projected for the lifetimes of the migrants and their first-generation descendants. Accordingly, the net fiscal burden was projected and discounted to the present. In this way, the net fiscal burden for each age cohort of migrants was calculated in present value terms. Within each age cohort, these calculations were disaggregated according to three educational levels: Less than high school education, high school education, and more than high school education. The findings suggest that migrants with less than high school education are typically a net fiscal burden that can reach as high as approximately US- $\$ 100,000$ in present value, when the migrants' age on arrival is between 20-30 years.

Following the recent enlargement of the European Union to 27 countries there were concerns that the EU-15 was likely to face a rise in welfare migration. Hans-Werner Sinn (Financial Times, July 12th 2004) made a somewhat 
alarming prediction:

"There will be more migration in Europe, but it will be 'bad' migration as well as 'good'.'Good' migration is driven by wage and productivity difference. 'Bad' migration is driven by generosity of the welfare state."

Nevertheless, only three members of the EU-15 (the UK, Sweden and Ireland) allowed free access for residents of the accession countries to their national labor markets, in the year of the first enlargement, 2004. The other members of the EU-15 took advantage of the clause that allows for restricted labor markets for a transitional period of up to seven years. Focusing on the UK and the A8 countries ${ }^{2}$, Dustmann at al (2009) bring evidence of no welfare migration. The average age of the A8 migrants during the period $2004^{3}-2008$ is 25.8 years, considerably lower than the native U.K. average age (38.7 years). The A8 migrants are also better educated than the natives. For instance, the percentage of those that left full-time education at the age of 21 years or later is 35.5 among the A8 migrants, compared to only 17.1 among the U.K. natives. Another indication that the migration is not predominantly driven by welfare motives is the higher employment rate of the A8 migrants $(83.1 \%)$ relative to the U.K. natives $(78.9 \%)$. Furthermore, for the same period, the contribution of the A8 migrants to government revenues far exceeded the government expenditures attributed to them. A recent study by Barbone et al (2009), based on the 2006 European Union Survey of Income and Living conditions, finds that migrants from the accession countries constitute only 1-2 percent of the total population in the pre-enlargement EU countries (excluding Germany and Luxemburg); by comparison about 6 percent of the population in the latter EU countries were born outside the enlarged EU. The small share of migrants from the accession countries is, of

\footnotetext{
${ }^{2}$ The A8 countries are the first eight accession countries (Czech Republic, Estonia, Hungary, Latvia, Lithuania, Slovenia and Poland.)

${ }^{3}$ More accurately, the said period extends from the second quarter of 2004 through the first quarter of 2009.
} 
course, not surprising in view of the restrictions imposed on migration from the accession countries to the EU-15 before the enlargement and during the transition period after the enlargement. The study shows also that there is, as expected, a positive correlation between the net current taxes (that is, taxes paid less benefits received) of migrants from all source countries and their education level ${ }^{4}$.

Indeed the general public perceives unskilled migrants as a drain on the public finance. In the U.K., the Daily Mirror (24 July, 2006) puts it bread and butter terms: "Economic migrants need schools for their children. They need housing .They need medical care. They can even lose their jobs."

Not unexpectedly, employing opinion surveys, Hanson et al (2007) bring evidence that in the United States native residents of states which provide generous benefits to migrants also prefer to reduce the number of migrants. Furthermore, the opposition is stronger among higher income groups. Similarly, Hanson et al (2009), again employing opinion surveys, find for the United States that native-born residents of states with a high share of unskilled migrants, among the migrants population, prefer to restrict in migration; whereas native-born residents of states with a high share of skilled migrants among the migrant population are less likely to favor restricting migration (see also Mayda (2006) for work along the same line). Indeed, developed economies do attempt to sort out immigrants by skills (see, for instance, Bhagwati and Gordon (2009)). Australia and Canada employ a point system based on selected immigrants' characteristics. The U.S. employs explicit preference for professional, technical and kindred immigrants under the so-called third-preference quota. Jasso and Rosenzweig (2009) find that both the Australian and American selection mechanisms are effective in sorting out the skilled migrants, and produce essentially similar outcomes despite of their different legal characteristics.

The organization of the paper is as follows. Section 1 presents the analytical framework. Section 2

\footnotetext{
${ }^{4}$ See also Boeri, Hanson, and McCormick (2002)
} 


\section{Analytical Framework}

Consider a standard two-period, overlapping-generations model. The old cohort retires, while the young cohort works. There are two skill levels: skilled and unskilled. The welfare-state is modeled simply by a proportional tax on labor income to finance a demogrant or public services in a balancedbudget manner ${ }^{5}$. Therefore, some (the unskilled workers and old retirees) are net beneficiaries from the welfare state and others (the skilled workers) are net contributors to it. Migration policies are set to determine the total migration volume and its skill composition. We characterize Markov-perfect politico-economic equilibria consisting of the tax rate (which determines the demogrant), skill composition and the the total number of migrants. We distinguish between two voting behaviors: sincere and strategic voting.

\subsection{Preferences and Technology}

The utility of each individual in period $t$, for young and old, is given, respectively, by

$$
\begin{aligned}
U^{y}\left(c_{t}^{y, i}, l_{t}^{i}, c_{t+1}^{o}\right) & =c_{t}^{y, i}-\frac{\varepsilon\left(l_{t}^{i}\right)^{\frac{1+\varepsilon}{\varepsilon}}}{1+\varepsilon}+\beta c_{t+1}^{o}, i=s, u \\
U^{o}\left(c_{t}^{o}\right) & =c_{t}^{o} .
\end{aligned}
$$

where, $s$ and $u$ denote skilled and unskilled labor. Here, $y$ and $o$ denote to young and old, $l^{i}$ is labor, $\varepsilon$ is the elasticity of the labor supply, and $\beta \in(0,1)$ is the discount factor. Note that $c_{t}^{o}$ is the consumption of an old individual at period $t$ (who was born in period $t-1$ ). Young and old agents in the economy maximize the above utility functions subject to their respective budget constraints as follows:

$$
\begin{aligned}
c_{t}^{y, i}+s_{t} & \leq\left(1-\tau_{t}\right) w_{t}^{i} l_{t}^{i}+b_{t} \\
c_{t}^{o} & \leq\left(1+r_{t}\right) s_{t-1}+b_{t}
\end{aligned}
$$

\footnotetext{
${ }^{5}$ We draw on Sand and Razin (2007) and Suwankiri (2009).
} 
where $s_{t}, \tau_{t}, w_{t}^{i}$, and $b_{t}$ denote saving of the young agents in period $t$, the linear income tax rate, wage for labors with different skills, and the lump-sum transfer (more on tax rate and transfer below).

Given the linearity of $U$ in $c_{t}$ and $c_{t+1}$, the only equilibrium interest rate $r$ equals $\frac{1}{\beta}-1$ and individuals have no incentive to either save or dissave. For convenience, we set saving at zero. ${ }^{6}$ This essentially reduces the two groups of old retirees (skilled and unskilled) to just one because they have identical preference irrespective of their skill level. Therefore, the budget constraints for the young and old in period $t$, respectively, are $c_{t}^{y, i} \leq\left(1-\tau_{t}\right) w_{t}^{i} l_{t}^{i}+b_{t}$ and $c_{t}^{o} \leq b_{t}$. In addition to decision on consumption, the young also decide on how much labor to supply. Individual's labor supply is given by

$$
l_{t}^{i}=\left(w_{t}^{i}\left(1-\tau_{t}\right)\right)^{\varepsilon}, i=s, u
$$

where $w^{i}$ is the wage rate of a worker of skill level $i=s, u$.

There is just one good, which is produced by using the two types of labor as perfect substitute with constant marginal products. ${ }^{7}$ The production function is given by

$$
Y_{t}=w^{s} L_{t}^{s}+w^{u} L_{t}^{u}
$$

where $L_{t}^{i}$ is the aggregate labor supply of skill $i=s, u$. Labor markets are competitive, ensuring the wages going to the skilled and unskilled workers are indeed equal to their marginal products, $w^{s}$ and $w^{u}$, respectively. We naturally assume that $w^{s}>w^{u}$.

We denote the demogrant by $b_{t}$ and the tax rate by $\tau_{t}$. The agents in the economy take these policy variables as given when maximizing their utilities.

\footnotetext{
${ }^{6}$ In fact, any saving level is an optimal choice. Assuming no saving is for pure convenience. With saving, since old individuals do not work the last period of their life, they will consume savings plus any transfer. Through both these channels, the old individuals benefit from migration. See Forni (2005), and Sand and Razin (2007).

${ }^{7}$ This simplification, nonetheless, allows us to focus solely on the linkages between the welfare state and migration, leaving aside any labor market consideration. For an analysis to the other extreme, in which there are only labor market considerations, see Ortega (2005). In the appendix, we lay out a framework where the two inputs are imperfect substitutes with diminishing marginal products.
} 
Because the old generation has no income, its only source of income comes from the demogrant. The model yields the following indirect utility function (recall that saving is zero):

$$
\begin{aligned}
V^{y, i} & =\frac{\left(\left(1-\tau_{t}\right) w^{i}\right)^{1+\varepsilon}}{1+\varepsilon}+b_{t}+\beta b_{t+1} \\
V^{o} & =b_{t},
\end{aligned}
$$

for $i \in\{s, u\}$. For brevity, we will use $V^{i}$ to denote $V^{y, i}$ because only the young workers need to be distinguished by their skill level.

In addition to the parameters of the welfare state $\left(\tau_{t}\right.$ and, consequently, $\left.b_{t}\right)$, the political process also determines migration policy. This policy consists of two parts: one determining the volume of migration, and the other its skill composition. We denote by $\mu_{t}$ the ratio of allowed migrants to the native-born young population and denote by $\sigma_{t}$ the fraction of skilled migrants in the the total number of migrant entering the country in period $t$. Migrants are assumed to have identical preference to the native-born. We assume all migrants come young and they are naturalized one period after their entrance. Hence, they gain voting rights when they are old.

Let $s_{t}$ denote the fraction of native-born skilled workers in the labor force in period $t$ (where $s_{0}>0$ ). The aggregate labor supply in the economy of each type of labor is given by

$$
L_{t}^{s}=\left[s_{t}+\sigma_{t} \mu_{t}\right] N_{t} l_{t}^{s}
$$

and

$$
L_{t}^{u}=\left[1-s_{t}+\left(1-\sigma_{t}\right) \mu_{t}\right] N_{t} l_{t}^{u}
$$

where $N_{t}$ is the number of native-born young individuals in period $t$.

\subsection{Demographic Dynamics}

The dynamics of the economy are given by two dynamic equations: one governs the aggregate population, while the other governs the skill composition 
dynamics. Because skills are not endogenous within the model, we assume for simplicity that the offspring replicate exactly the skill level of their parents. ${ }^{8}$ That is,

$$
\begin{aligned}
N_{t+1} & =\left[1+n+(1+m) \mu_{t}\right] N_{t} \\
s_{t+1} N_{t+1} & =\left[(1+n) s_{t}+(1+m) \sigma_{t} \mu_{t}\right] N_{t},
\end{aligned}
$$

where $n$ and $m$ are the population growth rates of the native-born population and the migrants, respectively. We plausibly assume that $n<m \leq 1$, and we allow the population growth rates to be negative. Combining the two equations above together, we get the dynamics of the labor supply of skilled native-born as follows:

$$
s_{t+1}=\frac{(1+n) s_{t}+(1+m) \sigma_{t} \mu_{t}}{1+n+(1+m) \mu_{t}} .
$$

Equation (8) implies that the fraction of the native-born skilled in the nativeborn labor force will be higher in period $t+1$ than in period $t$ if the proportion of skilled migrants in period $t$ is higher than that of the native-born, that is, if $\sigma_{t}>s_{t}$. Naturally, when there is no migration the share of skilled workers out of (native-born) young population does not change over time, by assumption. When migration is allowed and its share of skilled labor is larger than that of the native-born, the share of skilled labor in the population will grow over time.

\subsection{The Welfare-State System}

We model the welfare-state system as balanced period-by-period. In essence, it operates like a pay-as-you-go system. The proceeds from the labor tax of rate $\tau_{t}$ in period $t$ serve entirely to finance the demogrant $b_{t}$ in the same

\footnotetext{
${ }^{8}$ Razin, Sadka, and Swagel (2002b), and Casarico and Devillanova (2003) provide a synthesis with endogeneous skill analysis. The first work focussed on the shift in skill distribution of current population, while the latter studied skill-upgrading of future population.
} 
period. Therefore, the equation for the demogrant, $b_{t}$, is given by

$$
b_{t}=\frac{\tau_{t}\left(\left(s_{t}+\sigma_{t} \mu_{t}\right) w^{s} N_{t} l_{t}^{s}+\left(1-s_{t}+\left(1-\sigma_{t}\right) \mu_{t}\right) w^{u} N_{t} l_{t}^{u}\right)}{\left(1+\mu_{t}\right) N_{t}+\left(1+\mu_{t-1}\right) N_{t-1}},
$$

which upon some manipulation reduces to

$$
b_{t}=\frac{\tau_{t}\left(\left(s_{t}+\sigma_{t} \mu_{t}\right) w^{s} l_{t}^{s}+\left(1-s_{t}+\left(1-\sigma_{t}\right) \mu_{t}\right) w^{u} l_{t}^{u}\right)}{1+\mu_{t}+\frac{1+\mu_{t-1}}{1+n+\mu_{t-1}(1+m)}},
$$

where the individual's labor supplies are given above in equation (3). It is straightforward to see that a larger $\sigma_{t}$ increases the demogrant (recall that $w^{s} l_{t}^{s}>w^{u} l_{t}^{u}$ ). That is, a higher skill composition of migrants brings about higher tax revenues, and, consequently, enables more generous welfare state, other things being equal. Similarly, upon differentiation of $b_{t}$ with respect to $\mu_{t}$, we can conclude that a higher volume of migration enables a more generous welfare system if the share of the skilled among the migrants exceeds the share of the skilled among the native-born workers $\left(\sigma_{t}>s_{t}\right)$.

\section{Political Economy Equilibrium: Sincere Vot- ing}

In this section, we study the politico-economic equilibrium in the model. First, we begin our analysis with "sincere voting", where individuals vote according to their sincere preference irrespective of what the final outcome of the political process will be. In this case, the outcome of the voting is determined by the largest voting group. ${ }^{9}$ Therefore, it is important to see who forms the largest voting group in the economy and under what conditions. Note that there are only three voting groups: the skilled nativeborn young, the unskilled native-born young, and the old (recall that there is no saving, so that all the old care only about the size of the demogrant and thus have identical interest.

\footnotetext{
${ }^{9}$ Evidently, this assumption amounts to majority voting when there are only two voting groups.
} 
1. The group of skilled native-born workers is the largest group ("the skilled group") under two conditions. First, its size must dominates the unskilled young, and, second, it must also dominate the old cohort. Algebraically, these are

$$
s_{t}>\frac{1}{2}
$$

and

$$
s_{t}>\frac{1+\mu_{t-1}}{1+n+\mu_{t-1}(1+m)},
$$

respectively. It can be shown that, because $n<m \leq 1$, only the second of the two conditions is sufficient.

2. The group of unskilled native-born workers is the largest group ("the unskilled group") under two similar conditions; that are reduced to just one:

$$
1-s_{t}>\frac{1+\mu_{t-1}}{1+n+\mu_{t-1}(1+m)} .
$$

3. The group of old retirees is the largest group ("the old group"), when its size is larger than each one of the former groups, that is,

$$
\frac{1+\mu_{t-1}}{1+n+\mu_{t-1}(1+m)} \geq \max \left\{s_{t}, 1-s_{t}\right\} .
$$

With some algebra, one can straightforward demonstrate that this partitions the state space $(0,1)$ into three parts: when $s_{t}<\frac{n+\mu_{t-1} m}{1+n+\mu_{t-1}(1+m)}$ (the unskilled workers are the largest group), when $s_{t} \in\left[\frac{n+\mu_{t-1} m}{1+n+\mu_{t-1}(1+m)}, \frac{1+\mu_{t-1}}{1+n+\mu_{t-1}(1+m)}\right]$ (the old retirees are the largest group, and when $s_{t}>\frac{1+\mu_{t-1}}{1+n+\mu_{t-1}(1+m)}$ (the skilled workers are the largest group).

\subsection{Equilibrium}

We first describe what are the variables relevant for each of the three types of voters when casting the vote in period $t$. First, $s_{t}$ is the variable which describes the state of the economy. Also, each voter takes into account how 
her choice of the policy variables in period $t$ will affect the chosen policy variables in period $t+1$ which depends on $s_{t+1}$ (recall that the benefit she will get in period $t+1, b_{t+1}$, depends on $\tau_{t+1}, \sigma_{t+1}$, and $\left.\mu_{t+1}\right)$. Therefore each voter will cast her vote on the set of policy variables $\tau_{t}, \sigma_{t}$, and $\mu_{t}$ which maximizes her utility given the values of $s_{t}$, taking also into account how this will affect $s_{t+1}$. Thus, there is a link between the policy chosen in period $t$ to the one chosen in period $t+1$. The outcome of the voting is the triplet of the policy variables most preferred by the largest voting group.

The mechanism (policy rule or function) that characterizes the choice of the policy variables $\left(\tau_{t}, \sigma_{t}\right.$, and $\left.\mu_{t}\right)$ is invariant over time. This mechanism relates the choice in any period to the choice of the preceding period $\left(\tau_{t-1}, \sigma_{t-1}\right.$, and $\left.\mu_{t-1}\right)$. This choice depend also on the current state of the economy, $s_{t}$. Thus, we are looking for a triplet policy function $\left(\tau_{t}, \sigma_{t}, \mu_{t}\right)=$ $\Phi\left(s_{t}, \tau_{t-1}, \sigma_{t-1}, \mu_{t-1}\right)$, which is a solution to the following functional equation

$$
\begin{array}{r}
\Phi\left(s_{t}\right)=\underset{\tau_{t}, \sigma_{t}, \mu_{t}}{\arg \max } V^{d}\left\{s_{t}, \tau_{t}, \sigma_{t}, \mu_{t}, \Phi\left(s_{t+1}\right)\right\} \\
\text { s.t. } s_{t+1}=\frac{(1+n) s_{t}+(1+m) \sigma_{t} \mu_{t}}{1+n+(1+m) \mu_{t}},
\end{array}
$$

where $V^{d}$ is the indirect utility function of the decisive voter $d$, and $d \in$ $\{s, u, o\}$ is the identity of the largest voting group in the economy.

This equation states that the decisive (largest) group in period $t$ chooses, given the state of the economy $s_{t}$, the most preferred policy variables $\tau_{t}, \sigma_{t}$, and $\mu_{t}$. In doing so, this group realizes that her utility is affected not only by these (current) variables, but also the policy variables of the next period $\left(\tau_{t+1}, \sigma_{t+1}, \mu_{t+1}\right)$. This group further realizes that the future policy variables are affected by the current variables according to the policy function $\Phi\left(s_{t+1}, \tau_{t}, \sigma_{t}, \mu_{t}\right)$. Furthermore, this inter-temporal functional relationship between the policy variables in periods $t+1$ and $t$ is the same as the one existed between period $t$ and $t-1$. Put differently, what the decisive group in period $t$ chooses is related to $s_{t}, \tau_{t-1}, \sigma_{t-1}$, and $\mu_{t-1}$ in exactly the same way (through $\Phi(\cdot)$ ) as what the decisive group in period $t+1$ is expected to be related to $s_{t+1}, \tau_{t}, \sigma_{t}$, and $\mu_{t}$. 
Denoting the policy function, $\Phi\left(s_{t}, \tau_{t-1}, \sigma_{t-1}, \mu_{t-1}\right)$, by $\left(\tau_{t}, \sigma_{t}, \mu_{t}\right)$, we can show that the outcomes of the policy rule are:

$$
\begin{aligned}
& \tau_{t}=\left\{\begin{array}{ccc}
\frac{1-\frac{1}{J}}{1+\varepsilon-\frac{1}{J}} & , \text { if } s_{t} \in\left[0, \frac{n+m \mu_{t-1}}{1+n+\mu_{t-1}(1+m)}\right) \\
\frac{1}{1+\varepsilon} & , \text { if } s_{t} \in\left[\frac{n+m \mu_{t-1}}{1+n+\mu_{t-1}(1+m)}, \frac{1+\mu_{t-1}}{1+n+\mu_{t-1}(1+m)}\right] \\
0 & & \text { if } s_{t} \in\left(\frac{1+\mu_{t-1}}{1+n+\mu_{t-1}(1+m)}, 1\right]
\end{array}\right. \\
& \sigma_{t}=\left\{\begin{array}{c}
, \text { if } s_{t} \in\left[0, \frac{n+m \mu_{t-1}}{1+n+\mu_{t-1}(1+m)}\right) \\
1, \text { if } s_{t} \in\left[\frac{n+m \mu_{t-1}}{1+n+\mu_{t-1}(1+m)}, \frac{1+\mu_{t-1}}{1+n+\mu_{t-1}(1+m)}\right] \\
\text { or if } s_{t} \in\left(\frac{1+\mu_{t-1}}{1+n+\mu_{t-1}(1+m)}, \frac{1}{1+n}\right) \\
\widehat{\sigma}<\frac{1}{2}
\end{array}\right. \\
& \mu_{t}=\left\{\begin{array}{rr}
\frac{1-(1+n) s_{t}}{m}, & \text { if } s_{t} \in\left[0, \frac{n+m \mu_{t-1}}{1+n+\mu_{t-1}(1+m)}\right) \text { and } \Psi>0 \text { or } \\
\text { or if } s_{t} \in\left(\frac{1+\mu_{t-1}}{1+n+\mu_{t-1}(1+m)}, \frac{1}{1+n}\right) \\
1 \quad, \text { if } s_{t} \in\left[0, \frac{n+m \mu_{t-1}}{1+n+\mu_{t-1}(1+m)}\right) \text { and } \Psi \leq 0 \\
\widehat{\mu}<1 & \text { or if } s_{t} \in\left[\frac{n+m \mu_{t-1}}{1+n+\mu_{t-1}(1+m)}, \frac{1+\mu_{t-1}}{1+n+\mu_{t-1}(1+m)}\right] . \\
\text {, if } s_{t} \in\left[\frac{1}{1+n}, 1\right]
\end{array}\right.
\end{aligned}
$$

where

$$
\begin{aligned}
J & =\frac{\left(s_{t}+\sigma_{t} \mu_{t}\right)\left(\frac{w_{t}^{s}}{w_{t}^{u}}\right)^{1+\varepsilon}+1-s_{t}+\left(1-\sigma_{t}\right) \mu_{t}}{1+\mu_{t}+\frac{1+\mu_{t-1}}{1+n+\mu_{t-1}(1+m)}} \\
\Psi & =b_{t}^{u}+\beta b_{t+1}^{o}-\widehat{b}_{t},
\end{aligned}
$$

where we denote by $\widehat{b}_{t}$ the demogrant period $t$ with $\mu_{t}=1=\sigma_{t}$, and $b_{t}^{u}$ the demogrant in period $t$ with $\sigma_{t}=1$ and $\mu_{t}=\frac{1-(1+n) s_{t}}{m}$ (both demogrants are associated with the tax rate preferred by the unskilled group). Similarly, $b_{t+1}^{o}$ is the demogrant in period $t+1$ associated with the set of policy variables preferred by the old group.

Notice that the case $s_{t}>\frac{1}{1+n}$ cannot happen if the unskilled group is the largest (because $n<1$ ). In this case, the special migration policy variables preferred by the skilled group, $\widehat{\sigma}$, and $\widehat{\mu}$, are given implicitly from the 
maximization exercise

$$
\begin{aligned}
&\langle\widehat{\sigma}, \widehat{\mu}\rangle=\underset{\sigma_{t}, \mu_{t}}{\arg \max } V_{t}^{s}=\frac{\left(A_{t} w_{t}^{s}\right)^{1+\varepsilon}}{1+\varepsilon}+\beta b_{t+1}^{o} \\
& \text { s. t. } \quad(1+n) s_{t}+(1+m) \sigma_{t} \mu_{t} \leq 1+\mu_{t} .
\end{aligned}
$$

When the solution to the problem in (19) is interior, we can describe it by

$$
\frac{\frac{\partial V^{s}}{\partial \sigma_{t}}}{\frac{\partial V^{s}}{\partial \mu_{t}}}=\frac{\widehat{\mu}(1+m)}{(1+m) \widehat{\sigma}-1} .
$$

There are also two possible corner solutions: $\langle\widehat{\sigma}, \widehat{\mu}\rangle=\left\langle 0,(1+n) s_{t}-1\right\rangle$ and $\langle\widehat{\sigma}, \widehat{\mu}\rangle=\left\langle\frac{2-(1+n) s_{t}}{1+m}, 1\right\rangle$. We explain in details these results below.

We provide the dynamics of the economy below and discuss them briefly here.We start with the case when $s_{t}$ is close to zero. Let's assume that we are in the more interesting case in which $\Psi>0$ (we will provide detailed interpretations below). In that case, the unskilled young is the most numerous and forward looking. According to the policy rules, the policy should lean towards admitting more skilled immigrants, albeit restricting the size of immigration to ensure that the unskilled will control the voting power when old. Thus $s_{t}$ would increase, but not at the fastest rate. The fastest increase in $s_{t}$ will come when the old agents control the voting power and maximally admit skilled immigrants into the country. The rate of increase in $s_{t}$ will be the fastest when the old retirees form the largest group, or when $s_{t} \in\left[\frac{n+\mu_{t-1} m}{1+n+\mu_{t-1}(1+m)}, \frac{1+\mu_{t-1}}{1+n+\mu_{t-1}(1+m)}\right]$. Therefore, due to the increase in welfare benefit from admitting skilled immigrants, $s_{t}$ will continue to increase to the point where the largest group in the economy is the skilled young group. After $s_{t}$ crosses the threshold $\frac{1+\mu_{t-1}}{1+n+\mu_{t-1}(1+m)}$, the dynamics will exhibit cyclic behaviors as the young skilled workers try to place themselves as the largest 
old voters in the next period. The dynamics are given as follows:

$$
s_{t+1}=\left\{\begin{array}{cc}
\frac{1+m-(1+n) s_{t}}{1+m-(1+n)\left[(1+m) s_{t}-m\right]} & , \text { if } s_{t} \in\left[0, \frac{n+m \mu_{t-1}}{1+n+\mu_{t-1}(1+m)}\right) \\
\frac{(1+n) s_{t}+(1+m)}{2+n+m} & , \text { if } s_{t} \in\left[\frac{n+m \mu_{t-1}}{1+n+\mu_{t-1}(1+m)}, \frac{1+\mu_{t-1}}{1+n+\mu_{t-1}(1+m)}\right] \\
\frac{1+m-(1+n) s_{t}}{1+m-(1+n)\left[(1+m) s_{t}-m\right]} & , \text { if } s_{t} \in\left(\frac{1+\mu_{t-1}}{1+n+\mu_{t-1}(1+m)}, \frac{1}{1+n}\right) \\
\frac{(1+n) s_{t}+(1+m) \widehat{\sigma} \widehat{\mu}}{1+n+(1+m) \widehat{\mu}} & , \text { if } s_{t} \in\left[\frac{1}{1+n}, 1\right] .
\end{array}\right.
$$

\subsection{Interpretation: Migration and Tax Policies}

The intuition for the aforementioned results is as follows. The skilled is the net contributor to the welfare state, while the other two groups are net beneficiaries. We refer to Figure 1 for illustration. Preferences of the old retirees are simple. If the old cohort is the largest, it wants maximal welfare state benefits, which means taxing to the Laffer point $\left(\frac{1}{1+\varepsilon}\right)$. They also allow the maximal number of skilled migrants in to the economy because of the tax contribution this generates to the welfare system.

It is interesting to note that, although the unskilled young are net beneficiaries in this welfare state, they are, nevertheless, still paying taxes. Hence the preferred tax policy of the unskilled voters is smaller than the Laffer point with a wedge $\frac{1}{J}$, which we will provide further discussions on below. Clearly, the unskilled workers also prefer to let in more skilled immigrants due to their contribution to the welfare state. How many will they let in depends on the function $\Psi$, which weighs the future benefits against the cost at the present. Basically, if the unskilled workers are not forward-looking, it is in their best interest to let in as many skilled migrants as possible. However, this will lead to no redistribution in the next period because the skilled workers will be the largest. Hence, the function $\Psi$ is the difference between the benefits they get by being, as they are, forward-looking and being myopic.

The skilled native-born young prefer more skilled migrants for a different reason than the earlier two groups. They prefer to let in skilled migrants in this case because this will provide a higher number of skilled native workers 
Tax rate

Skill composition

Immigration volume
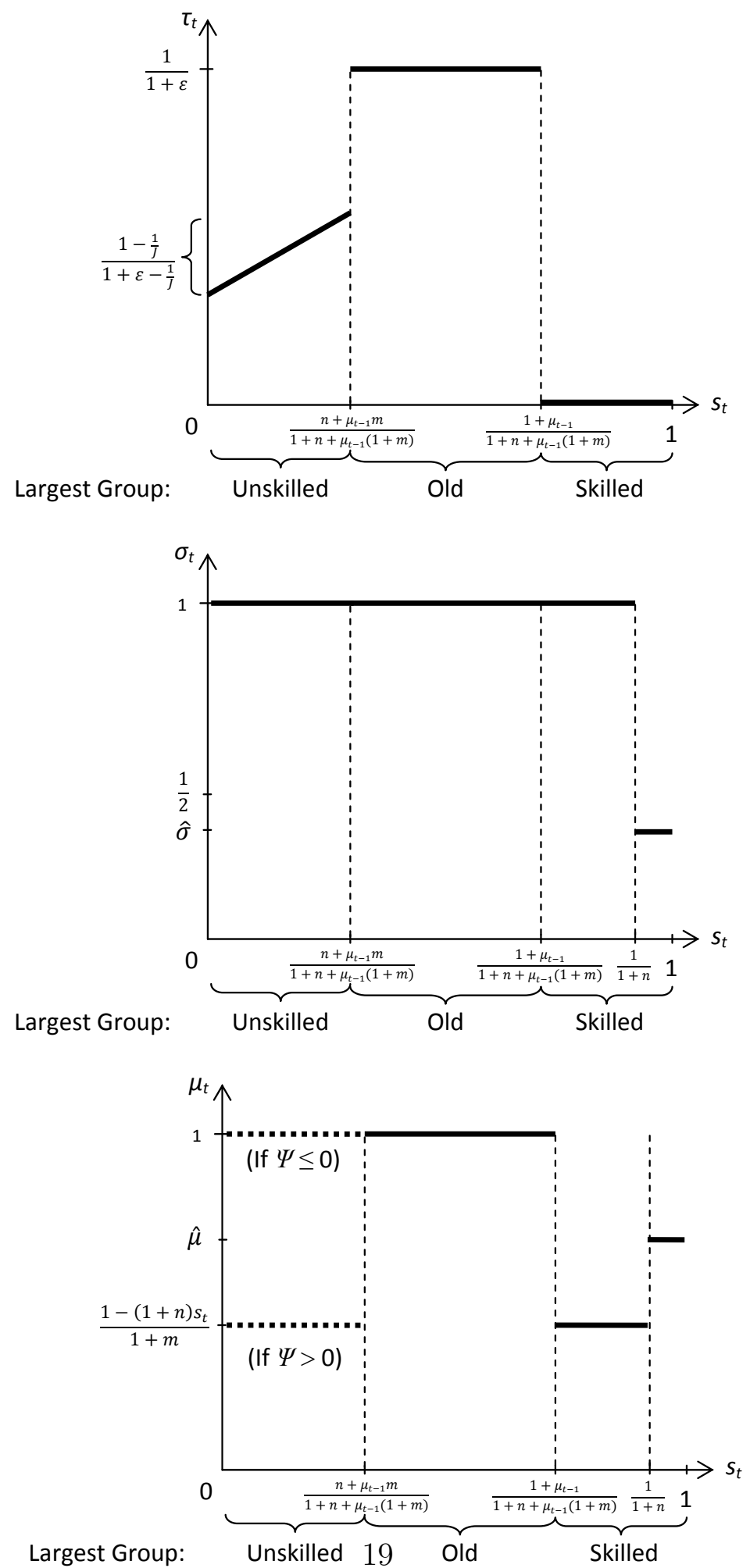

Figure 1: Policy Rules with Exogenous Wages 
in the next period. Thus, because the skilled are forward-looking, they too will prefer to have more skilled workers in their retirement period. However, they cannot let in too many of them because their high birth rate may render the skilled young in the next period as the largest group who will vote to abolish the welfare state altogether.

A common feature among models with Markov-perfect equilibrium is the idea that today's voters have the power to influence the identity of future policy makers. Such feature is also prominent in our analysis here. As previously pointed out in Dolmas and Huffman (2004), Ortega (2005), and Sand and Razin (2007), future political influence of migrants will matter for the decision on immigration policy today. The migration policy of either young group reflects this fact that they may want to put themselves as the largest group in the next period. Thus, instead of letting in too many migrants, who will give birth to a large new skilled generation, they will want to let in as much as possible before the threshold is crossed. This threshold is $\frac{1-(1+n) s_{t}}{m} .^{10}$ Letting $s_{t}=1$ gets the same result as Sand and Razin (2007). There are two differences nonetheless. First, the equilibrium here has a bite even if the population growth rate is positive, which cannot be done when there are only young and old cohort, unless there is a negative population growth rate as in their work. Another fundamental difference is that, in order to have some transfer in the economy, the young decisive largest group has a choice of placing the next period's decisive power either in the hand of next period's unskilled or the old. So we need to verify an additional condition that it is better for this period's decisive young to choose the old generation next period, which is the case.

When $s_{t} \geq \frac{1}{1+n}$, we have a unique situation (which is only possible when $n>0$ ). In this range of values, the number of skilled is growing too fast to be curbed by reducing migration volume alone. To ensure that the decisive

\footnotetext{
${ }^{10}$ One can easily verify that, given $\sigma_{t}=1$, the immigration quota that will put the old generation as the largest group in the next period must satify $\mu_{t} \in$ $\left[n-(1+n) s_{t}, \frac{1-(1+n) s_{t}}{m}\right]$.
} 
power of the next period lands in the right hand, that is, the old, the skilled voters (who are the largest in this period) must make the unskilled cohort grow to weigh down the growth rate of the skilled workers. This is done by restricting both the skill composition as well as the size of total migration. ${ }^{11}$

The tax choice of the unskilled young deserves an independent discussion. In Razin, Sadka and Swagel (2002a, 2002b), it is maintained that the "fiscal leakage" to the native-born and to the migrants who are net beneficiaries may result in a lower tax rate chosen by the median voter. They assume that all migrants possess lower skill than the native-born. Because this increases the burden on the fiscal system, the median voter votes to reduce the size of the welfare state, instead of increasing it. To see such a resemblance the our result, we must first take the migration volume, $\mu_{t}$, and the skill composition, $\sigma_{t}$, as given. Letting $\tau_{t}^{u}$ denote the tax rate preferred by the unskilled group, one can verify from equation (17) that $\frac{\partial \tau_{t}^{u}}{\partial \sigma_{t}}>0$, and there exists $\bar{\sigma}$ such that, for any $\sigma_{t}<\bar{\sigma}$, we have $\frac{\partial \tau_{t}^{u}}{\partial \mu_{t}}<0$. Conversely, for any $\sigma_{t}>\bar{\sigma}$, we would get an expansion of the welfare state, because $\frac{\partial \tau_{t}^{u}}{\partial \mu_{t}}>0 .{ }^{12}$ Therefore, the higher number of skilled migrants will prompt a higher demand for intragenerational redistribution. The fiscal leakage channel shows that unskilled migration creates more fiscal burden, such that the decisive "unskilled" voters would rather have the welfare state shrunken. In addition, an increase in inequality in the economy, reflected in the skill premium $\left(\frac{w_{t}^{s}}{w_{t}^{u}}\right)$, leads to a

\footnotetext{
${ }^{11}$ Empirically, with the population growth rate of the major host countries for migration like the U.S. and Europe going below 1\%, it is unlikely that this case should ever be of much concern. Barro and Lee (2000) provides an approximation of the size of the skilled. While Barro and Lee statistics capture those 25 years and above, they also cite OECD statistics which capture age group between 25 and 64 . The percentage of this group who received tertiary education or higher in developed countries falls in the range of $15 \%$ to $47 \%$.

${ }^{12}$ Recall that the tax rate preferred by the unskilled young workers is less than the level that is preferred by the old retirees. The tax rate preferred by the old retirees, $\tau_{t}^{o}=\frac{1}{1+\varepsilon}$ is the Laffer point that attains the maximum welfare size, given immigration policies. Therefore the size of the welfare state is monotonic in the tax rate when $\tau \in\left[0, \frac{1}{1+\varepsilon}\right]$. Thus, our use of "shrink" and "expand" is justified.
} 
larger welfare state demanded by the unskilled.

\subsection{Policy Rules: Endogenous Wages}

In the appendix, we extend the model to incorporate endogenous wages. The following policy profile forms a Markov-perfect equilibrium with sincere voting:

$$
\begin{aligned}
& \tau_{t}=\left\{\begin{array}{crl}
\frac{1-\frac{1}{K}}{1+\varepsilon-\frac{1}{K}} & , \text { if } s_{t} \in\left[0, \frac{n+m \mu_{t-1}}{1+n+\mu_{t-1}(1+m)}\right) \\
\frac{1}{1+\varepsilon} & , \text { if } s_{t} \in\left[\frac{n+m \mu_{t-1}}{1+n+\mu_{t-1}(1+m)}, \frac{1+\mu_{t-1}}{1+n+\mu_{t-1}(1+m)}\right] \\
0 & , \text { if } s_{t} \in\left(\frac{1+\mu_{t-1}}{1+n+\mu_{t-1}(1+m)}, 1\right]
\end{array}\right. \\
& \sigma_{t}=\left\{\begin{array}{cl}
1 & , \text { if } s_{t} \in\left[0, \frac{1+\mu_{t-1}}{1+n+\mu_{t-1}(1+m)}\right] \\
\sigma_{t}^{s} & , \text { if } s_{t} \in\left(\frac{1+\mu_{t-1}}{1+n+\mu_{t-1}(1+m)}, 1\right]
\end{array}\right. \\
& \mu_{t}=\left\{\begin{array}{ccc}
1 & , \text { if } s_{t} \in\left[0, \frac{n+m \mu_{t-1}}{1+n+\mu_{t-1}(1+m)}\right) \text { and } \widehat{\Psi} \leq 0 \\
\frac{1-(1+n) s_{t}}{m} & , \text { if } s_{t} \in\left[\frac{n+m \mu_{t-1}}{1+n+\mu_{t-1}(1+m)}, \frac{1+\mu_{t-1}}{1+n+\mu_{t-1}(1+m)}\right] \\
\mu_{t}^{s} & \text { if } s_{t} \in\left[0, \frac{n+m \mu_{t-1}}{1+n+\mu_{t-1}(1+m)}\right) \text { and } \widehat{\Psi}>0 \\
& , \text { if } s_{t} \in\left(\frac{1+\mu_{t-1}}{1+n+\mu_{t-1}(1+m)}, 1\right]
\end{array}\right.
\end{aligned}
$$

where, $\sigma^{s}$ and $\mu^{s}$ are given below, and $K$ and $\widehat{\Psi}$ are

$$
\begin{aligned}
K & =\frac{1-s_{t}+\left(1-\sigma_{t}\right) \mu_{t}}{(1-\alpha)\left(1+\mu_{t}+\frac{1+\mu_{t-1}}{1+n+\mu_{t-1}(1+m)}\right)} \\
\widehat{\Psi} & =V_{t}^{u}\left(\sigma_{t}=1, \mu_{t}=\frac{1-(1+n) s_{t}}{m}, \tau_{t}^{u}\right)-V_{t}^{u}\left(\sigma_{t}=1, \mu_{t}=1, \tau_{t}^{u}\right),
\end{aligned}
$$

with $\tau_{t}^{d}$ is the tax rate preferred by $d \in\{s, u, o\}$. For period $t$, the unskilled voters seem to prefer $\sigma_{t}^{u}=1$. However, before drawing a definite conclusion, we must compare the two levels of utility generated by completely allowing for maximum possible skilled immigrants and restricting them in order to be the decisive voter in the next period. The unskilled young would try to 
influence next period's identity of the decisive voter if and only if

$$
V_{t}^{u}\left(\sigma_{t}=1, \mu_{t}=\frac{1-(1+n) s_{t}}{m}, \tau_{t}^{u}\right)>V_{t}^{u}\left(\sigma_{t}=1, \mu_{t}=1, \tau_{t}^{u}\right),
$$

which compares the forward looking payoff with the myopic payoff as in the fixed-wage setting.

As for the native-born skilled workers, the situation becomes increasingly more complex with endogeneous wages. Their preferred tax rate for this period is still zero, $\tau_{t}^{s}=0$. However, skilled immigrants generate both cost and benefit to the native-born skilled workers. They provide a direct labor market competition, forcing the current skilled wage down. Ideally, the skilled natives would have preferred all unskilled immigrants for this reason. However, skilled immigrants also provide future benefits through higher transfer in the next period. This conflict makes their policy choices unclear. One thing is clear, nevertheless, the skilled voters will always believe that there is positive future benefit once they retired. To see this, consider if they think the skilled will for the majority next period, hence $T_{t+1}^{s}=0$. Then the only gain from immigrants would come from bringing as many unskilled in as possible to lift up the wage. That leads to $\sigma_{t}=0$, and $\mu_{t}=1$, which in turn will make the unskilled voters the largest in the next period. But this produces a contradiction to the initial belief of the skilled. Hence we know that, if the skilled voters form the largest group in this period, next period's decisive voter will either be the unskilled workers or the old. With this information, there are two problems to solve. First, if next period's decisive voter is unskilled, then the utility accrued to the skilled is

$$
\begin{aligned}
& V_{t}^{s \mid u}=\max _{\sigma_{t}, \mu_{t} \in[0,1] \times[0,1]} V_{t}^{s}=\alpha^{1+\varepsilon \alpha}(1-\alpha)^{\varepsilon(1-\alpha)} A_{t}^{1+\varepsilon}\left(\frac{1-s_{t}+\mu_{t}\left(1-\sigma_{t}\right)}{s_{t}+\mu_{t} \sigma_{t}}\right)^{1-\alpha}+\beta b_{t+1}^{u} \\
& \text { s.t. } \quad n+\mu_{t} m \geq(1+n) s_{t}+(1+m) \sigma_{t} \mu_{t} .
\end{aligned}
$$

If the decisive voter in the next period is controlled by the old, the utility to 
this period's skilled young is

$$
\begin{aligned}
& V_{t}^{s \mid o}=\max _{\sigma_{t}, \mu_{t} \in[0,1] \times[0,1]} V_{t}^{s}=\alpha^{1+\varepsilon \alpha}(1-\alpha)^{\varepsilon(1-\alpha)} A_{t}^{1+\varepsilon}\left(\frac{1-s_{t}+\mu_{t}\left(1-\sigma_{t}\right)}{s_{t}+\mu_{t} \sigma_{t}}\right)^{1-\alpha}+\beta b_{t+1}^{o} \\
& \text { s.t. } \quad 1+\mu_{t} \geq(1+n) s_{t}+(1+m) \sigma_{t} \mu_{t} \\
& \text { and } \quad(1+n) s_{t}+(1+m) \sigma_{t} \mu_{t} \geq n+\mu_{t} m .
\end{aligned}
$$

We denote with $V_{t}^{s \mid u}$ and $V_{t}^{s \mid o}$ the utility received by the skilled workers given that, respectively, the unskilled young and the old form the largest group in the next period. Note that the constraints need not be binding. The solution to each problem could lie entirely in the interior of the constraint set. To conclude on the policy choices of the skilled young, they must be such that $\left\langle\sigma_{t}^{s}, \mu_{t}^{s}\right\rangle=\arg \max \left\{V_{t}^{s \mid u}, V_{t}^{s \mid o}\right\}$.

\subsection{Interpretation}

Notice that the policy rules look very similar to the scenario with fixed wages (see Figure 2). Nonetheless, all incentives that drive the preference of agents in the economy come through two channels: wage and demogrant. The demogrant channel is similar to what we previously discussed under fixed wages. In addition now, through the wage channel, the unskilled workers benefit from complementarity with the skilled workers, lifting up their wage. Hence the unskilled young prefers even more skilled immigration. The function $\widehat{\Psi}$ is the difference between the utility they get by being forward-looking and myopic, similar to the fixed wage setup. The labor market channel is reversed for the skilled workers, who now prefer unskilled immigrants due to their wage complementarity and shun skilled migrants due to their competitive substitution. Nonetheless, the preference of the skilled workers is no longer as simple. On the one hand, they prefer unskilled over the skilled immigrant because of the labor market interaction. On the other hand, they want to bring more skilled immigrants whose skilled children would help support the welfare state in the next period. (Recall that the tax rate, and consequently the demogrant, for this period is zero when the largest group is 


\section{Endogenous wages}

Tax rate

Skill composition

Immigration

volume
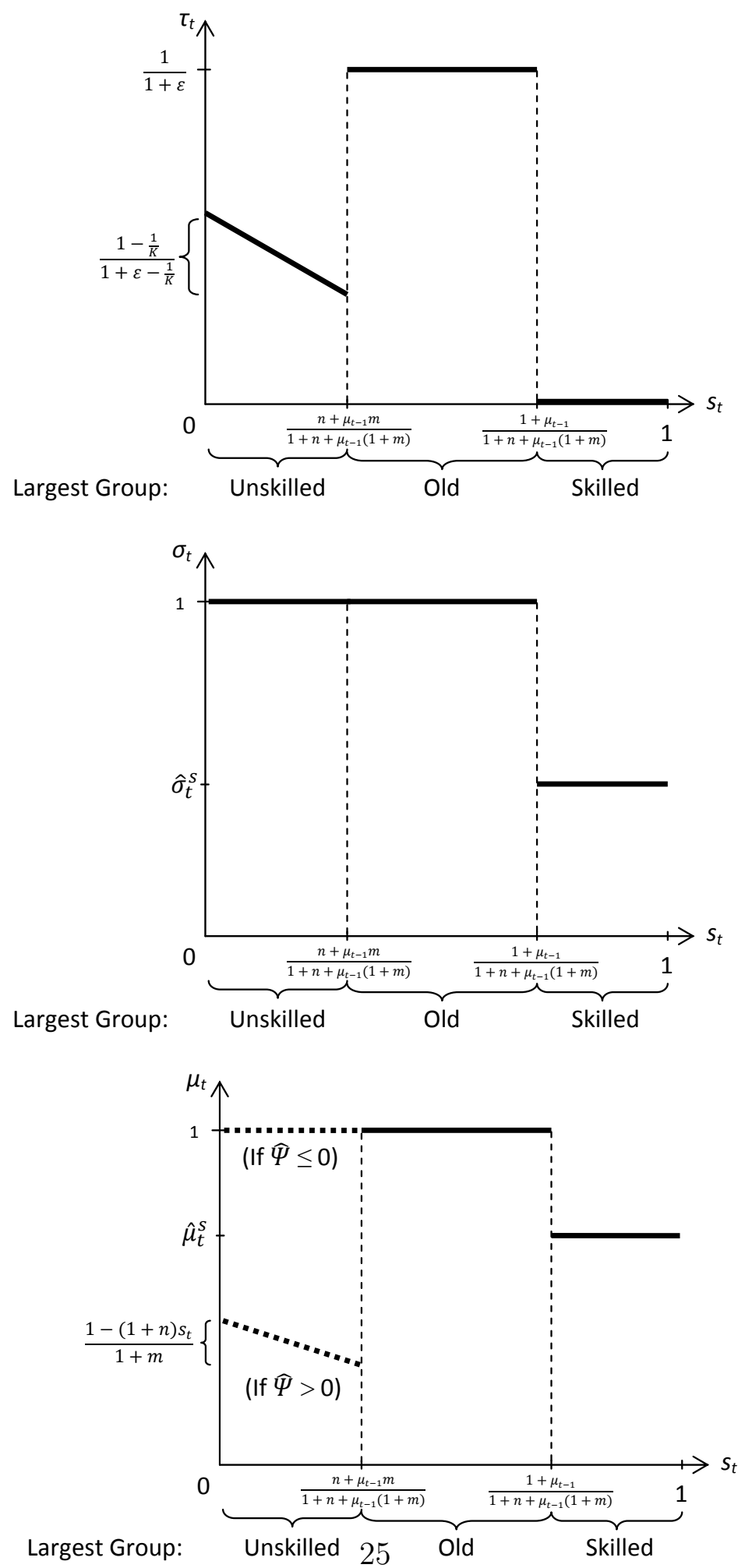

Figure 2: Policy Rules with Endogenous Wages 
skilled. As before, the immigration choices reflect the strategy of the younger cohort trying to place its older self as the largest group of voters in the next period.

It is worthwhile to consider the tax preference of the unskilled young in details. We first take immigration volume, $\mu_{t}$, and immigration composition, $\sigma_{t}$, as exogeneous. Inequality plays an even more important role in the tax preference of the unskilled under flexible wages. When, $1-\alpha$, the share of income going to the unskilled workers falls, tax rate rises to redistribute more heavily. This can be thought along the line of higher inequality leads to more redistribution. In fact, more accurately, the relevant measure of inequality for this expression is share of the income over the share of population, (1 $\alpha) / 1-s_{t}+\left(1-\sigma_{t}\right) \mu_{t}\left(1+\mu_{t}+\frac{1+\mu_{t-1}}{1+n+\mu_{t-1}(1+m)}\right)$. As this rises, the demand for redistribution falls. This makes it clear that the bottom line for the size of the welfare state is inequality as perceived by the unskilled voters.

A quick observation reveals that $\frac{\partial \tau_{t}^{u}}{\partial \sigma_{t}}<0$ for $\mu_{t}>0$ and $\frac{\partial \tau_{t}^{u}}{\partial s_{t}}<0$. That is, more skilled population in the economy leads to lowering the tax burden. This is completely opposite to the case under fixed wages. Under fixed wages, more number of skilled population implies more intra-generational redistribution. With flexible wages, any increase in the skilled composition increases both the unskilled wage and demogrant, while lowering the skilled wage. By lowering tax rate, the unskilled workers get to enjoy higher benefits from wage complementarity with skilled workers and from lower tax on the fruit of their labor, albeit lower demogrant. In sum, the larger skill composition in the economy (both of the native-born and the immigrants) automatically lowers inequality in the economy, hence the need for intra-generational redistribution.

The fiscal leakage channel also reflects these automatic correction in wage differential across the two working groups. It can be shown that there exists a cut-off immigrant skill composition, $\widetilde{\sigma}$, such that, for $\sigma_{t}<\widetilde{\sigma}$, we get an expansion of the welfare state, $\left(\frac{\partial \tau_{t}^{u}}{\partial \mu_{t}}>0\right)$, and for $\sigma_{t}>\widetilde{\sigma}$, we would get the opposite effect $\left(\frac{\partial \tau_{t}^{u}}{\partial \mu_{t}}<0\right)$. These inequalities are opposite to the case of fixed 
wages because inequality gets corrected by bringing in more skilled labor.

\section{$5 \quad$ Modelling Strategic Voting}

We now return to the model with exogenous wages and turn to strategic voting. In simple plurality electroral system, Duverger's Law postulates that the election will tend to be dominated by two main political parties (Duverger, 1954). To Duverger, this is due to "psychological effect" of voters who know that only the winning candidate gets to influence policies, so voters are careful to not waste their votes on candidates unlikely to win election. Hence, we adopt the following modern definition of strategic voting. Voters are voting strategically if they vote "... for a party they believe is more likely to win than their preferred party, to best influence who wins in the constituency" (Fisher, 2005). ${ }^{13}$ Recall that we have only three groups: the skilled nativeborn, the unskilled native-born, and the old. Let the set of three candidates be $\{s, u, o\}$, denoting their identity. Then, the decision to vote of any individual must be optimal under the correctly anticipated probability of winning and policy stance of each candidate. Because identical voters vote identically, we can focus on the decision of a representative voter from each group. To formalized the voting equilibrium, we let $e_{t}^{i} \in \triangle^{2}$ where $e_{t}^{i}=\left(\eta^{i}, \xi^{i}, \rho^{i}\right)$ be the vote of individual of type $i \in\{s, u, o\}$ cast and each coordinate represents the probabilistic vote an individual places on each candidate, the skilled, unskilled, and old candidate respectively, such that $\eta^{i}+\xi^{i}+\rho^{i}=1$. The voting decisions $\mathbf{e}_{t}^{*}=\left(e_{t}^{s *}, e_{t}^{u *}, e_{t}^{o *}\right)$ form a voting equilibrium at time $t$ if

$$
e_{t}^{i *}=\arg \max \left\{\sum_{j \in\{s, u, o\}} \mathcal{P}^{j}\left(e_{t}^{i}, \mathbf{e}_{-i t}^{*}\right) V^{i}\left(\Phi_{t}^{j}, \Phi_{t+1}, \mathbf{e}_{t+1}\right) \mid e_{t}^{i} \in \triangle^{2}\right\}
$$

\footnotetext{
${ }^{13}$ The literature does not seem to distinguish between strategic voting, as referred to by political studies in the U.S., and tactical voting, as referred to by political studies in the U.K. Also, we trade for tractability against new advancements in the theory of strategic voting in the literature, which attempt to model strategic voting situation as a global game (Myatt and Fisher, 2002; Myatt, 2007).
} 
for $i \in\{s, u, o\}$, where $\mathcal{P}^{j}\left(e_{t}^{i}, \mathbf{e}_{-i t}^{*}\right)$ denotes the probability that candidate $j \in\{s, u, o\}$ will win given the voting decisions, and $\mathbf{e}_{-i t}^{*}$ is the optimal voting decision of other groups that is not $i$, and $\Phi_{t}^{j}=\left(\tau_{t}^{j}, \sigma_{t}^{j}, \mu_{t}^{j}\right)$ is the policy vector if candidate $j$ wins. ${ }^{14}$ Thus we require that each vote cast by each group is a best-response to the votes by the other groups. In addition, the representative voter of each group must take into the account the pivotal power of their vote, because the entire group will also vote identically. The voting decision of the old voters is simple, because they have no concern for the future,

$$
e_{t}^{o *}=\arg \max \left\{\sum_{j \in\{s, u, o\}} \mathcal{P}^{j}\left(e_{t}^{o}, \mathbf{e}_{-o t}^{*}\right) V^{i}\left(\tau_{t}^{j}, \sigma_{t}^{j}, \mu_{t}^{j}\right) \mid e_{o t} \in \triangle^{2}\right\} .
$$

After the election, the votes for each candidate are tallied by adding up the size of votes that each group that has chosen to vote for the candidate. We further assume no commitment mechanism at the date of policy implementation. The candidate with the most votes wins the election and gets to implement his ideal set of policies.

Clearly, each individual prefers the ideal policies of their representative candidate. Strategic voting opens up the possibility of voting for someone else that is not the most preferred candidate in order to avoid the least favorable candidate, a collusion. For the skilled workers, they prefer the least amount of taxes and some migration for the future. Thus, they will prefer the policy choice of the unskilled over the old candidate because the tax rate will be lower. As for the old retirees, the higher the transfer benefits, the better. Clearly, the unskilled candidate promises some benefits whereas the skilled promises none, so old voters would prefer the policies of the unskilled over the skilled candidates. In sum, since the skilled and the old voters wnat to defeat the policies of one another, only two coalitions are possible irrespective of policy implemented: either unskilled collude with voters to upset the old

\footnotetext{
${ }^{14}$ The modeling of the voting equilibrium with strategic voting follows Besley and Coate (1997, 1998).
} 
voters, or the unskilled collude with the old voters to upset the skilled voters.

For the unskilled workers, both rankings are possible: they could either prefer the policy choice of the skilled over the old, or vice versa. The parameters of the model will dictate the direction of their votes. The cut-off tax policy, $\widetilde{\tau}$, is the break-even point for the unskilled between getting taxed but receiving transfer (policies of the old candidate) or pay no tax at all (policies of the skilled candidate).Formally, this tax level, $\widetilde{\tau}$, is defined implicitly by the equation

$$
\begin{aligned}
& \frac{\left(w^{u}\right)^{1+\varepsilon}}{1+\varepsilon}= \\
& \frac{\left((1-\widetilde{\tau}) w^{u}\right)^{1+\varepsilon}}{1+\varepsilon}+\frac{\widetilde{\tau}(1-\widetilde{\tau})^{\varepsilon}\left(\left(s_{t}+\sigma_{t} \mu_{t}\right)\left(w^{s}\right)^{1+\varepsilon}+\left(1-s_{t}+\left(1-\sigma_{t}\right) \mu_{t}\right)\left(w^{u}\right)^{1+\varepsilon}\right)}{1+\mu_{t}+\frac{1+\mu_{t-1}}{1+n+\mu_{t-1}(1+m)}} .
\end{aligned}
$$

We know that such a tax policy exists, because, taking next period's policies as given, the payoff in this period to the unskilled is maximized at its preferred policy and zero at $\tau=1$. Therefore, at some $\widetilde{\tau}$, the equality will hold. This cut-off tax rate will play an important role for the unskilled young' voting decision.

The main problem with ranking the utility streams of the voters is due to the multiplicity of future equilibria once we extend our work to strategic voting. This makes it impossible for the voters to get a precise prediction of what will happen as a result of their action today. Even if we could pin down all the relative sizes of all possible payoffs in the next period, multiple voting equilibria do not allow a prediction of which equilibrium will be selected in the future. To deal with the problem, we restrict the voting equilibrium to satisfy the stationary Markov-perfect property, similarly to the policy choices in previous section. Therefore, we are looking for the a triplet policy function $\left(\tau_{t}, \sigma_{t}, \mu_{t}\right)=\Phi\left(s_{t}, \mathbf{e}_{t}^{*}\right)$ with the voting decisions $\mathbf{e}_{t}^{*}$ that solve the following 
two problems:

$$
\begin{gathered}
\Phi\left(s_{t}, \mathbf{e}_{t}^{*}\right)=\underset{\tau_{t}, \sigma_{t}, \mu_{t}}{\arg \max } V^{d}\left(s_{t},, \tau_{t}, \sigma_{t}, \mu_{t}, \Phi\left(s_{t+1}, \mathbf{e}_{t+1}^{*}\right)\right) \\
\text { s.t. } s_{t+1}=\frac{(1+n) s_{t}+(1+m) \sigma_{t} \mu_{t}}{1+n+\mu_{t}(1+m)},
\end{gathered}
$$

where $d \in\{s, u, o\}$ is the identity of the the winning candidate, decided by the voting equilibrium $\mathbf{e}_{t}^{*}$ that satisfies the Markov perfect property and solves

$$
\begin{aligned}
e_{t}^{i *} & =\mathbf{e}^{*}\left(s_{t}\right) \\
& =\underset{e_{t}^{i} \in \triangle^{2}}{\arg \max } \sum_{j \in\{s, u, o\}} \mathcal{P}^{j}\left(e_{t}^{i}, \mathbf{e}_{-i t}^{*}\right) V^{i}\left(\Phi_{t}^{j}, \Phi\left(s_{t+1}, \mathbf{e}_{t+1}^{*}\right), \mathbf{e}^{*}\left(s_{t+1}\right)\right)
\end{aligned}
$$

where $\mathcal{P}^{j}\left(e_{t}^{i}, \mathbf{e}_{-i t}^{*}\right)$ denotes the winning probability of the representative candidate $j \in\{s, u, o\}$ given the voting decisions, and $\mathbf{e}_{-i t}^{*}$ is the optimal voting decision of other groups that is not $i$, and $\Phi_{t}^{j}=\left\langle\tau_{t}^{j}, \sigma_{t}^{j}, \mu_{t}^{j}\right\rangle$ is the vector of preferred policy of candidate from group $j$.

The stationary Markov-perfect equilibrium defined above introduces another functional equation exercise. The first exercise is to find a policy profile that satisfies the usual Markov-perfect definition, as discussed in the case of sincere voting in previous section. The second exercise restricts the voting decision to be cast on the belief that individuals in the same situation next period will vote in exactly the same way. With this property, the voters in this period know exactly how future generations will vote and can evaluate the stream of payoffs accordingly.

Lastly, the policies in voting equilibria are similar to those policies derived in the case of sincerely voting. This is consistent with the assumption that, after election, the winning candidate will implement his most ideal policies without any reelection motive. Hence any promise to deviate from this ideal point will be viewed as cheap talk in equilibrium. The policies are always coupled with a voting decision featuring the largest group always voting for its representative candidate (in line with literature on strategic voting which 
focusses primarily on the votes for the challengers, see Cox (1997), Fisher (2001, 2004), Myatt and Fisher (2002), and Myatt (2007)). In particular, if the group forms the majority by representing $50 \%$ or more of all voting population, all votes cast from this group will go to its representative candidate, who automatically gets to implement the policy under simple majority rule. This is an unintersting case as the analysis is identical to the sincere voting case above, so we leave it aside from our considerations for the moment. The economy can go through different equilibrium paths depending on $n, m$, and $s_{0}$, as follows:

1. If $n+m \leq 0$, the old group is always the majority. Tax rate is at the Laffer point and the economy is fully open to skilled migration.

2. If $n+m>0$, then the dynamics depend on the initial state of the economy, $s_{0}$. If $s_{0} \geq \frac{1+\frac{n}{2}}{1+n}$, then the skilled workers are the majority (controlling $50 \%$ of the population), and zero tax rate with limited skilled migration will be observed. If $\frac{n}{2(1+n)} \geq s_{0}$, the unskilled workers are the majority, then there will be a positive tax rate (less than at the Laffer point) and some skilled migration. If $n<0$, then initially the old cohort is the majority; the tax rate will be at the Laffer point and the skilled migration will be maximal. Otherwise, the policies implemented are given in the equilibrium below.

The first equilibrium we look at is dubbed "Intermediate" because it captures the essence that the preferred policies of the unskilled workers are a compromise from the extremity of the other two groups. We can show that the following strategy profile forms a Markov-perfect equilibrium with 
strategic voting

$$
\begin{aligned}
& e_{t}^{s *}= \begin{cases}(1,0,0) & , \text { if } s_{t}>\frac{1+\mu_{t-1}}{1+n+\mu_{t-1}(1+m)} \\
(0,1,0) & , \text { otherwise }\end{cases} \\
& e_{t}^{u *}=(0,1,0) \\
& e_{t}^{o *}=\left\{\begin{array}{l}
(0,0,1), \text { if } s_{t} \in\left[\frac{n+m \mu_{t-1}}{1+n+\mu_{t-1}(1+m)}, \frac{1+\mu_{t-1}}{1+n+\mu_{t-1}(1+m)}\right] \\
(0,1,0)
\end{array} \quad\right. \text { otherwise }
\end{aligned}
$$

and the policies implemented when no group is the absolute majority are

$$
\Phi_{t}=\left(\tau_{t}=\frac{1-\frac{1}{J}}{1+\varepsilon-\frac{1}{J}}, \sigma_{t}=1, \mu_{t}=\frac{2+n-2(1+n) s_{t}}{m}\right)
$$

where $J=J\left(\mu_{t}, \sigma_{t}, s_{t}, \mu_{t-1}\right)$ is as in equation (17).

The equilibrium features the unskilled voters always voting for their representative, whereas the other two groups vote for their respective candidate only if they are the largest group, or for the unskilled candidate otherwise. With these voting strategy, if no group captures $50 \%$ of the voting populations, the policy choice preferred by the unskilled candidate will prevail no matter who are the largest group in the constituency. One notable difference is the policy related to the immigration volume. In period $t+1$, as long as the skilled workers do not form $50 \%$ of the voting population, the policies preferred by the unskilled workers will be implemented. To make sure that this is the case, skilled migration is restricted to just the threshold that would have put the skilled voters as the absolute majority in period $t+1$. The volume of migration, $\mu_{t}^{*}=\frac{2+n-2(1+n) s_{t}}{m}$, reflects the fact that the threshold value for this variable can be pushed slightly farther. This level can be shown to be higher than the restricted volume in sincerely voting equilibrium.

In the preceding equilibrium, we let the preference of the skilled workers and the old retirees decide the fate of the policies. In the following analysis, the unskilled workers consider who they want to vote for. This will depend on how extractive the tax policy preferred by old is. We call the next equilibrium "Left-winged", because it features a welfare state of the size greater-or-equal 
to that of the intermediate policy equilibrium. This may arise when the tax rate preferred by the old voters is not excessively redistributive. When $\frac{1}{1+\varepsilon} \leq \widetilde{\tau}$, we have an equilibrium of the following form

$$
\begin{aligned}
& e_{t}^{s *}= \begin{cases}(1,0,0) & \text {, otherwise } \\
(0,1,0) & \text {, if } \frac{1+\mu_{t-1}}{1+n+\mu_{t-1}(1+m)} \geq s_{t} \geq \frac{1+\frac{n-m}{2}}{1+n}\end{cases}
\end{aligned}
$$

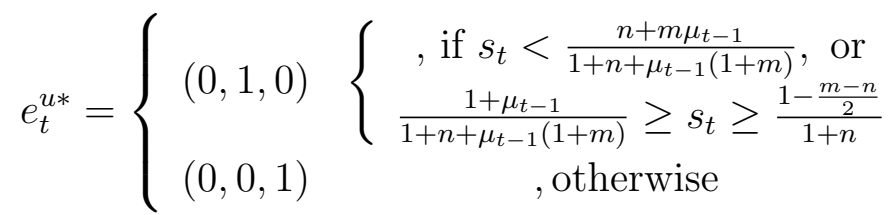

$$
\begin{aligned}
& e_{t}^{o *}=(0,0,1)
\end{aligned}
$$

and the policies implemented when no group is the absolute majority are

$\Phi_{t}=\left\{\begin{array}{cc}\left(\tau_{t}=\frac{1-\frac{1}{J}}{1+\varepsilon-\frac{1}{J}}, \sigma_{t}=1, \mu_{t}=\frac{2+n-2(1+n) s_{t}}{m}\right) & \text {, if } \frac{1+\mu_{t-1}}{1+n+\mu_{t-1}(1+m)} \geq s_{t} \geq \frac{1-\frac{m-n}{2}}{1+n} \\ \left(\tau_{t}^{*}=\frac{1}{1+\varepsilon}, \sigma_{t}=1, \mu_{t}=1\right) & , \text { otherwise }\end{array}\right.$

where $J=J\left(\mu_{t}, \sigma_{t}, s_{t}, \mu_{t-1}\right)$ is as in equation (17) and $\widetilde{\tau}$ is the cut-off tax rate given implicitly in equation (23).

When the tax rate preferred by the old voters is not excessively redistributive in the eyes of the unskilled, we could have an equilibrium where the unskilled voters strategically vote for the old candidate to avoid the policies preferred by the skilled voters, resulting in the implementation of the preferred policy of the old candidate even when the skilled voters form the largest group in the constituency. This will be an equilibrium when the size of the skilled is not "too large." Recall that, voting to implement the policies selected by the old candidate leads to opening the economy fully to the skilled immigrants. If the size of the skilled group is currently too large, there is a risk of making the skilled voters the decisive majority in the next period and will result in no welfare state in the retirement of this period's workers. The demographic cutoff level before this happens is given by $\frac{1-\frac{m-n}{2}}{1+n}$. Therefore, voting for the old will only be compatible with the interest of the unskilled voters when the tax rate is not excessively high and when the size of the 
skilled is not too large.

We turn our attention to the next equilibrium. When $\frac{1}{1+\varepsilon}>\widetilde{\tau}$, we can show that there is an equilibrium with the following functions:

$$
\begin{aligned}
& e_{t}^{s *}=\left\{\begin{array}{cc}
(1,0,0) & \text {, otherwise } \\
(0,1,0) & \text {,if } s_{t}<\frac{n+m \mu_{t-1}}{1+n+\mu_{t-1}(1+m)}
\end{array}\right. \\
& e_{t}^{u *}=\left\{\begin{array}{l}
(0,1,0) \\
(1,0,0)
\end{array} \quad \text { if } s_{t} \in\left[\frac{n+m \mu_{t-1}}{1+n+\mu_{t-1}(1+m)}, \frac{1+\mu_{t-1}}{1+n+\mu_{t-1}(1+m)}\right] .\right. \\
& e_{t}^{o *}=\left\{\begin{array}{cc}
(0,0,1) & \text {, otherwise } \\
(0,1,0) & \text {,if } s_{t}>\frac{1+\mu_{t-1}}{1+n+\mu_{t-1}(1+m)}
\end{array}\right.
\end{aligned}
$$

and the policies implemented when no group is the absolute majority are

$\Phi_{t}=\left\{\begin{array}{c}\left(\tau_{t}=0, \sigma_{t}=1, \mu_{t}=\frac{2+n-2(1+n) s_{t}}{m}\right) \\ \left(\tau_{t}=\frac{1-\frac{1}{J}}{1+\varepsilon-\frac{1}{J}}, \sigma_{t}=1, \mu_{t}=\frac{2+n-2(1+n) s_{t}}{m}\right)\end{array} \quad\right.$ if $s_{t} \in\left[\frac{n+m \mu_{t-1}}{1+n+\mu_{t-1}(1+m)}, \frac{1+\mu_{t-1}}{1+n+\mu_{t-1}(1+m)}\right]$

where $J=J\left(\mu_{t}, \sigma_{t}, s_{t}, \mu_{t-1}\right)$ is as in equation (17) and $\widetilde{\tau}$ is given in equation (23).

When the Laffer point is higher than $\widetilde{\tau}$, the tax rate is read as excessive $\mathrm{b}^{15} \mathrm{y}$ the unskilled voters. In this case, the unskilled voters will instead choose to vote for the skilled over the old candidate, resulting in the implementation of the preferred policy of the skilled candidate even when the old retirees form the largest group in the constituency. The resulting equilibrium as the size of the welfare state less-than-or-equal to that in the intermediate policy equilibrium, hence we refer to it as "Right-winged." When the tax preferred by the old is excessive from the perspective of the unskilled, the political process could implement the policies preferred by the skilled in order to avoid the worst possible outcome. This happens when the old voters constitute the largest group, and the unskilled voters vote strategically for the skilled

\footnotetext{
${ }^{15}$ This picture of extreme equilibrium is not in fact be realistic in actual elections due to incomplete information of supports and switching supports, see Myatt and Fisher (2001) and Myatt (2007).
} 
candidate. In other cases, however, the policies preferred by the unskilled will be implemented, irrespective of the identity of the largest group in the economy ${ }^{16}$.

The equilibrium under strategic outcome for the case of endogenous wages is similar to the case of fixed wages, given the new policy vectors, in the preceding section. Recall that for a policy rule to constitute a Markov-perfect equilibrium with sincere voting, the policy rule today must take into the account the policy variables that will be implemented in the future using the same policy rule. In particular, the decisive voter must consider the effect that today's policies will influence tomorrow's policies through the policies' influence on the state variable Recall that, under fixed wages, political coalitions are formed either between the skilled and the unskilled workers or between the old retirees and the unskilled workers. These formations continue to be true under the case of flexible wages. The skilled workers prefer the least number of skilled immigrants and the lowest level of tax. Thus they will prefer the policy choice of the unskilled over the old candidate. On the contrary, the old retirees want the highest degree of skilled immigrants and the maximal size of the welfare state. Hence they will prefer the policy choice of the unskilled over the skilled candidate. Which candidate the unskilled

\footnotetext{
${ }^{16}$ For our results with multidimensional policies, it is important to note here that the ranking of candidates by individual voters allows us to escape the well-known agendasetting cycle (the "Condorcet paradox"). Such a cycle, which arises when any candidate could be defeated in a pairwise majority voting competition, leads to massive indeterminacy and non-existence of a political equilibrium. The agenda-setting cycle will have a bite if the rankings of the candidates for all groups are unique: no group occupies the same ranked position more than once. However, this does not arise here, because, in all equilibria, some political groups have a common enemy. That is, because they will never vote for the least-preferred candidate (the "common" enemy), the voting cycle breaks down to determinate policies above, albeit their multiplicity. This occurs when voters agree on who is the least-preferred candidate and act together to block her from winning the election. The literature typically avoids the Condorcet paradox by restricting political preferences with some ad hoc assumptions. For our case, the preferences induced from economic assumption lead to the escape of the Condorcet paradox. For discussions on agenda-setting cycle, see Drazen (2000, page 71-72), and Persson and Tabellini (2000, page 29-31).
} 
workers decide to vote for depends on the gain from the labor and the degree of redistribution of the Laffer point. All in all, the equilibria will look identical to the one described in the preceding section.

\section{Strategic Voting: Dynamics}

We turn our attention to the dynamics of the economy now that the voters have the freedom to vote strategically. With multiple equilibria and no equilibrium selection mechanism, it is almost impossible to precisely trace out the dynamics of economy. Fortunately, we can impose one additional assumption about strategic voting to narrow immensely down the dimesions spanned by all equilibrium paths. Theoretical studies into Duvergerian outcome such as Cox (1997) led to a conclusion that supporters of lower-ranked challengers may choose to abandon their preferred candidate to vote instead for one of the two most popular leading candidates. As Myatt and Fisher (2001) put it, " $[\mathrm{s}]$ ometimes voters would rather abandon their preferred candidate to vote for another with a better chance of winning so as best to influence the outcome of the election." Such a switch may further trigger a bandwagon effect of more switching from lower-ranked to the top-two runners. In the extreme case, the process continues until we reach a Duvergerian equilibrium, only two candidates receive votes, while the rest receive none. In light of this literature, we further assume that in most of the time only the smallest group in time $t$ can vote strategically in time $t$ unless not supported by the voting equilibrium, in which case, we will apply the voting equilibrium which appears to most resemble a Schelling's focal piont (Schelling, 1980). Equipped with this new assumption, we can partition the state space into different segments according voting strategy as follows.

First, when $s_{t} \in\left[0, \frac{n+m \mu_{t-1}}{2\left(1+n+\mu_{t-1}(1+m)\right)}\right)$, the unskilled workers from the decisive majority, and elect their candidate to implement their most preferred policies: intermediate welfare state with some skilled immigrants, but not the maximal admission (recall that they must be careful with skilled immi- 


\begin{tabular}{r|ccccccc} 
& 0 & $\frac{n+m \mu_{t-1}}{2\left(1+n+\mu_{t-1}(1+m)\right)}$ & $\frac{n+m \mu_{t-1}}{1+n+\mu_{t-1}(1+m)}$ & $\frac{1}{2}$ & $\frac{1+\mu_{t-1}}{1+n+\mu_{t-1}(1+m)}$ & $\frac{2+n+\mu_{t-1}(2+m)}{2\left(1+n+\mu_{t-1}(1+m)\right)}$ & 1 \\
Majority & Unskilled & & & & & Skilled \\
\hline Largest & & Unskilled & Old & Old & Skilled & \\
\hline $2^{\text {nd }}$ Largest & Old & Old & Unskilled & Skilled & Old & Old \\
\hline Smallest & Skilled & Skilled & Skilled & Unskilled & Unskilled & Unskilled \\
\hline
\end{tabular}

Figure 3: Transition of sizes of each political group for every $s_{t} \in[0,1]$

gration policy not to place the skilled offsprings as the decisive majority in the next period when they are old). In this region, strategic voting does not matter. When $s_{t} \in\left[\frac{n+m \mu_{t-1}}{2\left(1+n+\mu_{t-1}(1+m)\right)}, \frac{n+m \mu_{t-1}}{1+n+\mu_{t-1}(1+m)}\right)$, the unskilled group is the largest, but not majority, the skilled group is the smallest. However, there is no strategic voting from the skilled voters to the old candidate as they stand on the opposite end of political spectrum. To the skilled, policies of the unskilled candidate are already more attractive than the policies of the old candidate. The next region is when $s_{t} \in\left[\frac{n+m \mu_{t-1}}{1+n+\mu_{t-1}(1+m)}, \frac{1}{2}\right)$, in which the old forms the largest group in the economy with the skilled being the smallest group. In this case, the skilled voters will strategically vote for the unskilled candidate to avoid Laffer point tax rate and maximal skilled migration. The collusion will be enough to overcome the size of old voters and push for implementation of the policies preferred by the unskilled candidate (given that $n+m>0)$. As $s_{t} \in\left[\frac{1}{2}, \frac{1-\frac{m-n}{2}}{1+n}\right)$, the largest group is still the old voters, while the smallest group switches to be the unskilled voters. If the Laffer tax rate is not too extractive $\left(\frac{1}{1+\varepsilon} \leq \widetilde{\tau}\right)$, the unskilled will not vote strategically for the skilled candidate. But if the tax rate is too extractive $\left(\frac{1}{1+\varepsilon}>\widetilde{\tau}\right)$, the unskilled will strategically vote for the skilled candidate to defeat the old candidate, hence implementing the preferred policies of the skilled candidate. A special case arises when $s_{t} \in\left[\frac{1-\frac{m-n}{2}}{1+n}, \frac{1+\mu_{t-1}}{1+n+\mu_{t-1}(1+m)}\right]$, the region in which the size of skilled is currently too large for the unskilled voters to risk putting the skilled voters as the decisive majority in the next period, 
killing the chance of having any welfare state in retirement. Hence both voting strategically or sincerely by the unskilled voters are no longer supported as an equilibrium unless the skilled voters choose to vote strategically for the unskilled candidate (the candidate with the smallest support) in order to defeat the old candidate. ${ }^{17}$ When $s_{t} \in\left(\frac{1+\mu_{t-1}}{1+n+\mu_{t-1}(1+m)}, \frac{2+n+\mu_{t-1}(2+m)}{2\left(1+n+\mu_{t-1}(1+m)\right)}\right)$, the skilled is now the largest group while the unskilled is the smallest group. However, since the size of skilled group is already so large, the unskilled voters will not vote strategically for the old candidate who will maximal open the economy to skilled migrants. Here, we again appeal the Schelling point's argument. While after observing the state variable, the old voters realize that their old candidate will not receive the strategic support from the unskilled voters and has no chance of defeating the skilled candidate. However, since the old voters prefer the policies of the unskilled over the skilled candidate, the unskilled voters know that the old voters are willing to support the unskilled candidate and its policy. Hence, the coalition with the old voters voting strategically for the unskilled candidate will be enough to defeat the status quo, the preferred policies of the skilled candidate. Lastly, when $s_{t} \in\left[\frac{2+n+\mu_{t-1}(2+m)}{2\left(1+n+\mu_{t-1}(1+m)\right)}, 1\right]$, the skilled voters form the decisive majority and implement their preferred policies irrespective of strategic voters. ${ }^{18}$

\footnotetext{
${ }^{17}$ Alternatively, the unskilled may choose to take a bitter pill by voting strategically for the skilled candidate in order to defeat the old candidate under the condition that the forgone welfare benefit today must be less than the discounted benefit in retirement. Otherwise, we revert back to what we think as more sensible collusion of skilled and unskilled for the intermediate policies preferred by unskilled candidate (Schelling point). This after all is an improvement for both the skilled and unskilled voters over the status quo (policies of the old).

${ }^{18}$ You may notice that the old voters are never the smallest group. This can be proven formally as follows. Suppose to the contrary that the old voters are the smallest group, that is $s_{t}>\frac{1+\mu_{t-1}}{1+n+\mu_{t-1}(1+m)}$ and $1-s_{t}>\frac{1+\mu_{t-1}}{1+n+\mu_{t-1}(1+m)}$. Adding the two inequalities yield $\frac{1}{2}>\frac{1+\mu_{t-1}}{1+n+\mu_{t-1}(1+m)}$. However, some algebra will reveal that $\frac{1+\mu_{t-1}}{1+n+\mu_{t-1}(1+m)} \in\left[\frac{1}{2}, 1\right]$ which produces a contradiction. Intuitively, for the old voters to be the smallest group, population growth rates must be $100 \%$ or higher! Otherwise, which ever way we slice the young generation into skilled and unskilled, one group will always be smaller than the old group.
} 
Below we explicitly write out the voting equilibrium associated with each partition of the state space. Voting vectors are in rows, so the first, second, and last row correspond to votes cast by the skilled, unskilled, and old voters respectively. The columns denote to whom the votes were casted for with the first, second, and last column correspond to voting for skilled, unskilled, and old candidate, respectively. Therefore, any off-diagonal vote imply strategic voting. The voting equilibria for the case of $\frac{1}{1+\varepsilon} \leq \widetilde{\tau}$ are as follows:

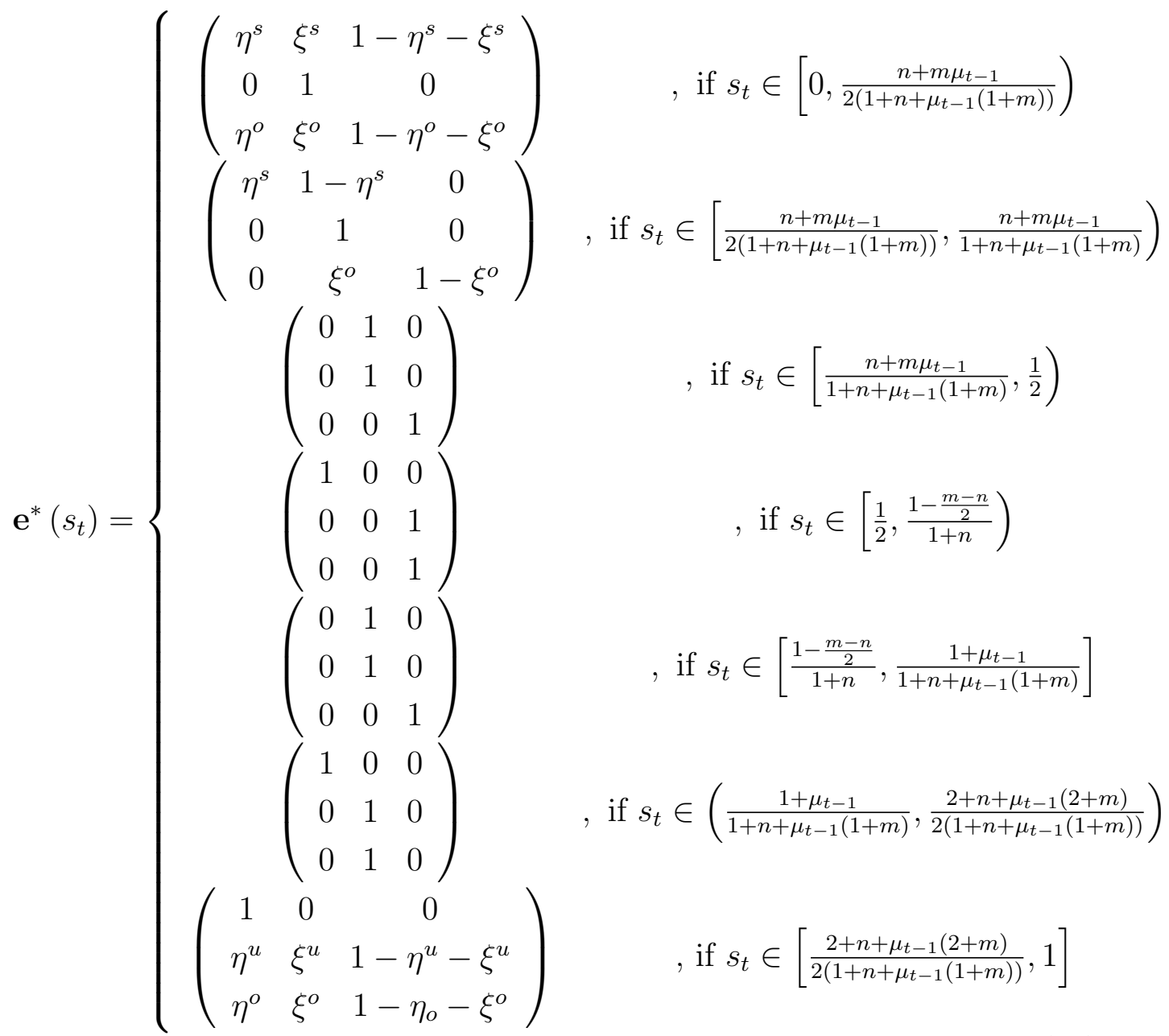

where $0 \leq \eta^{i}, \xi^{i} \leq 1$ are probabilistic vote of type $i \in\{s, u, o\}$ voters for the skilled and unskilled candidate, respectively. 
The dynamics of the economy are given as follows for the case of $\frac{1}{1+\varepsilon} \leq \widetilde{\tau}$ :

$$
s_{t+1}=\left\{\begin{array}{cc}
\frac{(1+m)(2+n)-(1+n)(2+m) s_{t}}{(1+m)(2+n)-(1+n)\left(2+m\left(2-s_{t}\right)\right)} & , \text { if } s_{t} \in\left[0, \frac{1}{2}\right) \\
\frac{(1+n) s_{t}+(1+m)}{2+n+m} & , \text { if } s_{t} \in\left[\frac{1}{2}, \frac{1-\frac{m-n}{2}}{1+n}\right) \\
\frac{(1+m)(2+n)-(1+n)(2+m) s_{t}}{(1+m)(2+n)-(1+n)\left(2+m\left(2-s_{t}\right)\right)} & , \text { if } s_{t} \in\left[\frac{1-\frac{m-n}{2}}{1+n}, \frac{1}{1+n}\right] \\
\frac{(1+n) s_{t}+(1+m) \widehat{\sigma} \hat{\mu}}{1+n+(1+m) \hat{\mu}} & , \text { if } s_{t} \in\left(\frac{1}{1+n}, 1\right] .
\end{array}\right.
$$

It is worthwhile to note that, although the dynamics appear similar to the sincere voting case, the voting game is much more complex than the above equations appear.

For the case $\frac{1}{1+\varepsilon}>\widetilde{\tau}$, the Laffer tax rate to too extractive for the unskilled workers, so the skilled and unskilled have incentives to try to block the old candidate from coming into power. In this case, there is no strategic voting from the unskilled voters to the old candidate, only for the skilled candidate. In this case, when $s_{t} \in\left[\frac{1}{2}, \frac{1+\mu_{t-1}}{1+n+\mu_{t-1}(1+m)}\right)$, the strategic coalition would successfully push for to implement of policies of the skilled candidate (unskilled voters vote strategically under the assumption that the smallest group will do so), hence $s_{t+1}=\frac{(1+m)(2+n)-(1+n)(2+m) s_{t}}{(1+m)(2+n)-(1+n)\left(2+m\left(2-s_{t}\right)\right)}$. As the skilled voters form the largest group, or $s_{t} \geq \frac{1+\mu_{t-1}}{1+n+\mu_{t-1}(1+m)}$, two possible coalitions could form in equilibrium. First, as in the "Right-winged" voting equilibrium above, the old voters could strategically vote for the unskilled candidate on top of votes by the unskilled voters to ensure the survival of the welfare state. However, if $s_{t} \geq \frac{1-\frac{m-n}{2}}{1+n}$, the size of skilled voters is already too large for fully opening the economy to skilled migration, so a coalition between skilled and unskilled voters comes into effect (which fits the above assumption that only the smallest group vote strategically). The second type of coalition continues until the skilled voters form the majority or $s_{t} \in\left[\frac{2+n+\mu_{t-1}(2+m)}{2\left(1+n+\mu_{t-1}(1+m)\right)}, 1\right]$. 


\section{Conclusion}

We develop and analyze a PAYG welfare system and migration policies in a political economy model that provides a resolution to tensions across generations and income groups. We built a dynamic politico-economic model featuring three groups of voters: skilled workers, unskilled workers, and retirees, with both inter- and intra-generational redistribution, resembling a welfare state. The skilled workers are net contributors to the welfare state whereas the unskilled workers and old retirees are net beneficiaries. We characterize the politico-economic equilibria of the tax rate, skill composition, and the total number of immigrants.

We show that, if the skilled workers are the decisive group, the tax rate will be minimal, while if the old retirees are the decisive group, the tax rate will be revenue-maximizing. When the decisive group is unskilled, the tax rate higher than zero, but less than the maximum revenue point. Interestingly, the difference between this tax rate the revenue-maximizing tax rate is negatively related to the measure of inequality, that is, the skill premium between the skilled and unskilled workers.

The native-born workers, whether skilled or unskilled, benefit from letting in migrants of all types, because their high birth rates can help increase the tax base in the next period. In this respect, skilled migrants help the welfare state more than unskilled migrants, to the extent that the offspring resemble their parents with respect to skill. In another respect, however, more migrants in the present will strengthen the political power of the young in the next period who, relatively to the old, are less keen on the generosity of the welfare state. Therefore, from this perspective, unskilled migrants pose less of a threat to the generosity of the welfare state then skilled migrants. When the skilled cohort grows rapidly, it may be necessary to bring in unskilled migrants to counter balance the expanding size of the skilled group to ensure the survival of the welfare state in the next period. The old retirees prefer maximum level of skilled immigrants.

When there are more than two groups of voters, as we have, coalitions 
between groups of voters will form in order to block another group's accession to power with strategic voting behavior. We find that two types of coalitions might be formed between the three groups of voters: between skilled-unskilled voters to block the old voters or between unskilled-old voters to block the skilled voters. As such, the ideal policies of the unskilled voters are featured more often in the political economy equilibria than any other groups regardless of the size of unskilled voters.

\section{References}

[1] Armenter, R. and F. Ortega (2011), "Credible Redistribution Policies and Skilled Migration," European Economic Review, 55, 228-245.

[2] Auerbach, A. and P. Oreopoulos (1999), "Analyzing the Economic Impact of U.S. Immigration," American Economic Review Papers and Proceedings, 89(2), 176-180.

[3] Bhagwati, Jagdish, and Gordon Hanson, eds (2009), Skilled Immigration Today: Problems, Prospects, and Policies, Oxford, UK: Oxford University Press.

[4] Benhabib, J. (1996), "On the Political Economy of Immigration," European Economic Review, 40, 1737-43.

[5] Besley, Timothy and Stephen Coate (1997), "An Economic Model of Representative Democracy," Quarterly Journal of Economics, 112(1), February, 85-114.

[6] Besley, Timothy and Stephen Coate (1998), "Sources of Inefficiency in a Representative Democracy: A Dynamic Approach," American Economic Review, 88(1), 139-156. 
[7] Blank, Rebecca M. (1988), "The Effect of Welfare and Wage Levels on the Location Decisions of Female-Headed Households." Journal of Urban Economics, 24, 186.

[8] Boeri, Tito, Gordon Howard Hanson and Barry McCormick (2002), Immigration Policy and the Welfare System: A Report for the Fondazione Rodolfo Debenedetti, Oxford University Press.

[9] Bohn, Henning (2005), "Will Social Security and Medicare Remain Viable as the U.S. Population Is Aging: An Update," In Robin Brooks and Assaf Razin (eds.), The Politics and Finance of Social Security Reform, Cambridge University Press, 44-72.

[10] Boldrin, M. and A. Rustichini (2000), "Political Equilibria with Social Security," Review of Economic Dynamics, 3, 41-78.

[11] Borjas, George J. (1999), Heaven's Door: Immigration Policy and the American Economy, Princeton University Press, Princeton, New Jersey.

[12] Brucker, Herbert, Gil Epstein, Barry McCormick, Gilles Saint-Paul, Alessandra Venturini, and Klaus Zimmerman (2001), "Managing Migration in the European Welfare State," mimeo, IZA Bonn, Germany.

[13] Casarico, Alessandra and Carlo Devillanova (2003), "Social Security and Migration with Endogenous Skill Upgrading," Journal of Public Economics, 87 (3-4), 773-797.

[14] Cohen, Alon, and Assaf Razin, "The Skill Composition of Immigrants and the Generosity of the Welfare State: Free versus Policy-controlled Migration," NBER Working Paper No. 144459, October.

[15] Cooley, T. F. and J. Soares (1999), " A Positive Theory of Social Security Based on Reputation," Journal of Political Economy, 107, 135-160.

[16] Cox, G. W. (1997), Making Votes Count: Strategic Coordination in the World's Electoral Systems, Cambridge University Press, Cambridge. 
[17] De Giorgi, Giacomo and Michele Pellizzari (2006), "Welfare Migration in Europe and the Cost of a Harmonized Social Assistance," IZA Discussion Paper No. 2094.

[18] Docquier, Frederic and Abdeslam Marfouk (2006), "International Migration by Educational Attainment 1990-2000," in Caglar Ozden and Maurice Schiff (eds.), International Migration, Remittances ad the Brain Drain, McMillan and Palgrave: New York.

[19] Docquier, Frederic, Oliver Lohest and Abdeslam Marfouk (2006), "What Determines Migrants' Destination Choice?," working paper.

[20] Dolmas, J. and G.W. Huffman (2004), "On the Political Economy of Immigration and Income Redistribution," International Economic Review, 45, 1129-68.

[21] Drazen, Alan (2000), Political Economy in Macroeconomics, Princeton University Press: New Jersey.

[22] Dustmann, C., Frattini, T. \& C. Halls (2009), "Assessing the Fiscal Costs and Benefits of A8 Migration to the U.K.", CReAM Discussion Paper No. 18/09.

[23] Duverger, Maurice (1954), Political Parties: Their Organization and Activity in the Modern State, New York: Wiley.

[24] Edmonston, Barry, and James P. Smith, editors, The New Americans: Economic, Demographic and Fiscal Effects of Immigration, National Academy Press, Washingtong, D.C.

[25] Enchautegui, Maria E. (1997), "Welfare Payments and Other Determinants of Female Migration," Journal of Labor Economics, 15, 529.

[26] Fisher, S. D. (2001), "Extending the Rational Voter Theory of Tactical Voting," (Paper presented at the Mid-West Political Science Association Meeting, Chicago, IL). 
[27] Fisher, S. D. (2005), "Definition and Measurement of Tactical Voting: The Role of Rational Choice," British Journal of Political Science, 34(1), 152-166.

[28] Forni, L. (2005), "Social Security as Markov Equilibrium in OLG Models," Review of Economic Dynamics, 8, 178-194.

[29] Frankel, Jeffrey A. and David Romer (1999), "Does Trade Cause Growth?," American Economic Review, 89(2), 379-399.

[30] Galasso, V. and P. Profeta (2002), "The Political Economy of Social Security: A Survey," European Journal of Political Economy, 18, 1-29.

[31] Gelbach, Jonah B. (2000), "The Life-cycle Welfare Migration Hypothesis: Evidence from the 1980 and 1990 Censuses," working paper.

[32] Gramlich, Edward M. and Deborah S. Laren (1984), "Migration and Income Redistribution Resposibilities," Journal of Human Resources, 19(4), 489.

[33] Hanson, Gordon H. (2008), "The Economic Consequence of the International Migration of Labor," NBER Working Paper No. 14490, November.

[34] Hanson, Gordon H., Kenneth Scheve, and Matthew J. Slaughter (2007), "Public Finance and Individual Preferences over Globalization Strategies," Economics and Politics, 19(1), March 1-33.

[35] Hanson, Gordon H., Kenneth Scheve, and Matthew J. Slaughter (2009), "Individual Preferences over High-Skilled Immigration in the United States," in Bhagwati, Jagdish and Gordon Hanson, editors, Skilled Immigration Today: Prospects, Problems, and Policies, Oxford University Press. 
[36] Hassler, John, Jose v. Rodriguez Mora, Kjetil Storesletten, and Fabrizio Zilibotti (2003). "The Survival of the Welfare State." American Economic Review, 93(1), pp. 87-112.

[37] Jasso, Guillermina and Mark R. Rosenzweig (2009), "Selection Criteria and the Skilll Composition of Immigratns: A Comparative Analysis of Australian and U.S. Employment Immigration," in Bhagwati, Jagdish and Gordon Hanson (2009), editors, Skilled Immigration Today: Prospects, Problems and Policies, Oxford University Press.

[38] Krusell, P. and J.V. Rios-Rull (1996), "Vested Interests in a Positive Theory of Stagnation and Growth," Review of Economic Studies, 63, 301-29.

[39] Lee, R. and T. Miller (2000), "Immigration, Social Security, and Broader Fical Impacts," American Economic Review Papers and Proceedings, 90(2), 350-354.

[40] Levine, Phillip B. and David J. Zimmerman (1999), "An Empirical Analysis of the Welfare Magnet Debate Using the NLSY," Journal of Population Economics, 12(3), 391.

[41] Mayda, Ann Maria (2006), "Who is against immigration? A crosscountry investigation of individual attitudes toward immigrants," Review of Economics and Statistics, 88(3), 510-530.

[42] McKinnish, Terra (2005), "Importing the Poor: Welfare Magnetism and Cross-Border Welfare Migration," Journal of Human Resources, 40(1), 57.

[43] Meyer, Bruce D. (2000), "Do the Poor Move to Receive Higher Welfare Benefits?," unpublished paper.

[44] Myatt, David P., and S. D. Fisher (2002), "Tactical Coordination in Plurality Electoral Sytems," Oxford Review of Economic Policy, 18 (4), 504-522. 
[45] Myatt, David P. (2007), "On the Theory of Strategic Voting," Review of Economic Studies, 74, 255-281.

[46] Ortega, F. (2005), Immigration Quotas and Skill Upgrading," Journal of Public Economics, 89(9-10), 1841-1863.

[47] Persson, Torsten and Guido Tabellini (2000), " Political Economics: Explaining Economic Policy, MIT Press: Cambridge, MA.

[48] Peridy, Nicolas (2006), "The European Union and Its New Neighbors: An Estimation of Migration Potentials," Economic Bulletin, 6(2), 1.

[49] Razin, Assaf and Efraim Sadka (1999), "Migration and Pension with International Capital Mobility," Journal of Public Economics, 74, 141150 .

[50] Razin, Assaf and Efraim Sadka (2004), "Welfare Migration: Is the Net Fiscal Burden a Good Measure of Its Economic Impact on the Welfare of the Native-born Population?," CESifo Economic Studies, 50(4), 709716 .

[51] Razin, Assaf, Efraim Sadka and Phillips Swagel (2002a), "The Aging Population and the Size of the Welfare State," Journal of Political Economy, 110, 900-918.

[52] Razin, Assaf, Efraim Sadka and Phillips Swagel (2002b), "Tax Burden and Migration: A Political Theory and Evidence," Journal of Public Economic, 85, 167-190.

[53] Sand, Edith, and Assaf Razin (2007), "The Political-Economy Positive Role of Social Security in Sustaining Migration (But Not Vice Versa)," NBER Working Paper 13598.

[54] Schelling, Thomas C. (1980), The Strategy of Conflict, Cambridge: Harvard University Press. 
[55] Scholten, U., and M.P. Thum (1996), "Public Pensions and Immigration Policy in a Democracy," Public Choice, 87, 347-361.

[56] Sinn, Hans-Werner (2003), "EU Enlargement, Migration, and Lessons from German Unification," German Economic Review, 1(3), 299 - 314.

[57] Southwick, Lawrence Jr. (1981), "Public Welfare Programs and Recipient Migration," Growth and Change, 12(4), 22.

[58] Storesletten, K. (2000), "Sustaining Fiscal Policy Through Immigration," Journal of Political Economy, 108(2), 300-323.

[59] Suwankiri, Benjarong (2009), "Three Essays in Dynamic Political Economy: Migration, Welfare State, and Poverty," Ph.D. Dissertation, unpublished: Cornell University.

[60] Walker, James (1994), "Migration Among Low-income Households: Helping he Witch Doctors Reach Consensus," unpublised paper. 


\section{A Appendix: Endogenous Wages}

In the appendix, we modify the production function to allow for endogeneous wages. We want to allow for interactions between two skill-groups in the production function, but in a parsimonious way. The production function should capture imperfect substitution between the two groups. Moreover, it should also display any complementarity effects one skill group may have on the other. To stay in line with all these requirements and parsimoniousness, we assume a Cobb-Douglas production function using two skills as inputs to produce a single consumption good. The output is therefore produced by the following production function:

$$
Y_{t}=\left(L_{t}^{s}\right)^{\alpha}\left(L_{t}^{u}\right)^{1-\alpha}
$$

where $\alpha$ is the share of skilled income. The labor markets are assumed to be competitive, hence the wage paid to the workers equal to marginal product of the final worker hired, that is

$$
w_{t}^{s}=\alpha\left(\frac{L_{t}^{u}}{L_{t}^{s}}\right)^{1-\alpha} \text { and } w_{t}^{u}=(1-\alpha)\left(\frac{L_{t}^{s}}{L_{t}^{u}}\right)^{\alpha} \text {. }
$$

The preference of agents in the economy is the same as in section 3, making the individual labor supply equals to

$$
l_{t}^{s}=\left(w_{t}^{s}(1-\tau)\right)^{\varepsilon} \text { and } l_{t}^{u}=\left(w_{t}^{u}(1-\tau)\right)^{\varepsilon},
$$

which can be aggregated to aggregate labor supplies as before. The two labor markets can be solved simultaneously to find the equilibrium wage for the skilled and unskilled workers, respectively yielding

$$
\begin{aligned}
& \left(w_{t}^{s}\right)^{1+\varepsilon}=\alpha^{1+\varepsilon \alpha}(1-\alpha)^{\varepsilon(1-\alpha)}\left(\frac{1-s_{t}+\mu_{t}\left(1-\sigma_{t}\right)}{s_{t}+\mu_{t} \sigma_{t}}\right)^{1-\alpha} \\
& \left(w_{t}^{u}\right)^{1+\varepsilon}=\alpha^{\varepsilon \alpha}(1-\alpha)^{1+\varepsilon(1-\alpha)}\left(\frac{s_{t}+\mu_{t} \sigma_{t}}{1-s_{t}+\mu_{t}\left(1-\sigma_{t}\right)}\right)^{\alpha} .
\end{aligned}
$$


From the production function, there is really no distinct difference between skilled and unskilled labor force, except from the fact that they are complementary to one another. To resolve this, we assume that $w_{t}^{s}>w_{t}^{u}$, which leads to $\alpha>\frac{s_{t}+\mu}{1+\mu}$. For sufficiency, we may assume $\alpha>\frac{1+s_{t}}{2}{ }^{19}$

\section{A.1 Balanced-Budget}

Similarly to the previous sections, the budget must be balanced in all periods. We can make use of equation (34) and (35) in the labor supply equations to simplify the balanced-budget equation as follows

$$
\begin{aligned}
& b_{t}\left(1+\mu_{t}+\frac{1+\mu_{t-1}}{1+n+\mu_{t-1}(1+m)}\right) \\
& =\tau_{t}\left(\left(s_{t}+\sigma_{t} \mu_{t}\right) w_{t}^{s} l_{t}^{s}+\left(1-s_{t}+\left(1-\sigma_{t}\right) \mu_{t}\right) w_{t}^{u} l_{t}^{u}\right) \\
& =\tau_{t}\left(1-\tau_{t}\right)^{\varepsilon} \alpha^{\varepsilon \alpha}(1-\alpha)^{\varepsilon(1-\alpha)}\left(s_{t}+\mu_{t} \sigma_{t}\right)^{\alpha}\left(1-s_{t}+\mu_{t}\left(1-\sigma_{t}\right)\right)^{1-\alpha} .
\end{aligned}
$$

The last equality follows from substituting for labor supply and wage equations and simplifying some algebra.

The last quantity necessary is the indirect utility of the young (as the indirect utility of the old is simply $T_{t}$ ), which is given by

$$
V_{t}^{h}=\frac{\left(1-\tau_{t}\right)^{1+\varepsilon}}{1+\varepsilon}\left(w_{t}^{h}\right)^{1+\varepsilon}+b_{t}+\beta b_{t+1}
$$

where $h \in\{s, u\}$ denotes the skill level of the individual. Wages are given in equation (34) and (35) for the skilled and unskilled, respectively, and the demogrant is from equation (36). Notice right away that, for the young, immigrants affect them through two contemporaneous channels. The first

\footnotetext{
${ }^{19}$ Given the nature of exogenously given skilled distribution and the simple skill dynamics (described in equation (8)), this inequality maybe broken in the very long run as $s_{t} \nearrow 1$ when $t \nearrow \infty$. We could alternatively assume a Markovian skill dynamics such that there positive probability of being unskilled, depending on family background. For the purpose of our positive analysis of period $t$ and $t+1$ in the proximity of non-binding condition, the assumption we make should suffice, as long as we refrain from making very long run inferences or steady-state behaviors of the political system.
} 
channel is through the labor markets, by either complementarity or substitutability. The second channel comes from financing higher redistribution and transfer in this period. 